\title{
不同耐低氮性玉米品种的花后碳氮积累与转运特征
}

\author{
吴雅薇蒲玮赵波魏桂孔凡磊袁继超”
}

四川农业大学农学院 / 农业部西南作物生理生态与耕作实验室 / 作物生理生态及栽培四川省重点实验室, 四川成都 611130

摘 要: 为了探明不同耐低氮性玉米品种生育后期碳、氮物质积累与转运特性及其对氮肥响应的差异, 以期为品种 高效施氮技术的制定提供理论依据。以耐低氮品种“正红 311’ (Zhenghong 311, ZH311)和低氮敏感品种“先玉 508’ (Xianyu 508, XY508)为材料, 设置 4 个氮肥用量 $\left(0 、 150 、 300\right.$ 和 $450 \mathrm{~kg} \mathrm{hm}^{-2}$ ), 于 2017-2019 年研究氮肥水平对不同 耐低氮性玉米品种生育后期物质, 包括干物质、全氮和非结构性碳水化合物(non-structural carbohydrate, NSC) 积累和 转运的影响。结果表明, 供氮不足时, 玉米通过增加花前咜存碳、氮物质对籽粒的转运以保证产量。增施氮肥能够提 高玉米花后干物质和碳水化合物生产及其对籽粒质量的贡献率。与低氮敏感品种先玉 508 相比, 在低氮条件下, 耐低 氮品种正红 311 在花前、花后均保持较高的植株干物质、NSC 和氮素量, 花后物质积累量及其对籽粒质量的贡献率 更高, 从而拥有更高的籽粒产量; 品种间花前物质转运率及其对籽粒质量的贡献率差异不大。面对低氮胁迫, 正红 311 既保证了花前咜存物质充分向籽粒运输，同时维持着较高的同化物积累能力来影响其产量形成。

关键词：耐低氮性; 玉米; 干物质; 氮素; 非结构性碳水化合物

\section{Characteristics of post-anthesis carbon and nitrogen accumulation and trans- location in maize cultivars with different low nitrogen tolerance}

\author{
WU Ya-Wei, PU Wei, ZHAO Bo, WEI Gui, KONG Fan-Lei, and YUAN Ji-Chao* \\ College of Agronomy, Sichuan Agricultural University / Key Laboratory of Crop Ecophysiology and Farming System in Southwest China, Ministry of \\ Agriculture / Crop Ecophysiology and Cultivation Key Laboratory of Sichuan Province, Chengdu 611130, Sichuan, China
}

\begin{abstract}
To understand the suitable amount of nitrogen (N) application and the potential of increasing yield and improve efficiency for the maize cultivars with different low N tolerance. The experiment was setting from 2017 to 2019 , the low-N tolerant cultivar 'Zhenghong 311 (ZH311)' and the low-N sensitive cultivar 'Xianyu 508 (XY508)' were selected and four N application rates $\left(0 \mathrm{~kg} \mathrm{hm}^{-2}, 150 \mathrm{~kg} \mathrm{hm}^{-2}, 300 \mathrm{~kg} \mathrm{hm}^{-2}\right.$, and $\left.450 \mathrm{~kg} \mathrm{hm}^{-2}\right)$ were set to investigate the effects of $\mathrm{N}$ level on carbon $(\mathrm{C})$ and $\mathrm{N}$ accumulation and translocation in the later growth stage of different maize cultivars. The results showed that in low $\mathrm{N}$ environment, maize increased the $\mathrm{C}$ and $\mathrm{N}$ translocations of pre-silking to the grain to ensure the yield. Increasing the $\mathrm{N}$ fertilizer applications could improve the contribution rates of dry matter and carbohydrate to grain yield. Compared with XY508, ZH311 had higher accumulations of plant dry matter, $\mathrm{N}$ and non-structural carbohydrate (NSC) of pre- and post-silking, and higher contribution rates of dry matter, $\mathrm{N}$ and accumulations to grain yield of post-silking, so it had higher grain yield. There was no significant difference between cultivars in the rate of dry matter, N and NSC translocation of pre-silking. In the face of low N stress, ZH 311 not only ensured the sufficient $\mathrm{C}$ and $\mathrm{N}$ translocations of pre-silking to the grain, but also maintained a higher capacity of assimilate accumulation to affect the yield formation.
\end{abstract}

Keywords: low nitrogen tolerance; maize; dry matter; nitrogen; non-structural carbohydrate

玉米是中国第一大粮食作物, 其产量直接关系 到我国粮食供应的安全 ${ }^{[1]}$ 。我国耕地面积有限, 其种
植面积难以再大幅增加, 因此提高单产成为主要目 标, 而施用化肥特别是氮肥是提高玉米单产的主要

本研究由国家重点研发计划项目(2018YFD0301206, 2017YFD0301704, 2016YFD0300307, 2016YFD0300209)项目资助。

This study was supported by the National Key Research and Development Program of China (2018YFD0301206, 2017YFD0301704, 2016YFD0300307, 2016YFD0300209).

*通信作者(Corresponding author): 袁继超, E-mail: yuanjichao5@163.com

第一作者联系方式: E-mail: wyw6140@163.com

Received (收稿日期): 2020-05-28; Accepted (接受日期): 2020-11-13; Published online (网络出版日期): 2020-12-23.

URL: https://kns.cnki.net/kcms/detail/11.1809.S.20201223.1437.010.html 
途径 ${ }^{[2]}$ 。在我国实际生产中, 农户通常通过投入大量 的氮肥来获取作物高产, 导致氮肥利用率 (nitrogen use efficiency, NUE)较低, 仅为 30\%左右, 远低于欧 美等发达国家 ${ }^{[3-4]}$ 。而且, 随着氮肥使用量的增加, 各种环境问题(土壤酸化、水土污染等)也随之而来, 这要求我们协调好玉米增产和 NUE 之间的关系。选 育氮高效型玉米品种是提高氮肥利用效率、确保玉 米增产的同时减少环境污染的有效途径之一 ${ }^{[5-6]}$ 。

作物的氮高效主要分 3 种: 一是作物在低氮素 水平下仍具有维持正常生长的能力, 并获得与正常 氮时相近的产量, 即低氮高效(耐低氮)型品种; 二 是随氮浓度增加, 植物吸收氮素养分并获得较高产 量的潜力, 即高氮高效型品种; 三是双高效型 ${ }^{[7-8]}$ 。 通常氮效率表示的是氮素投入与获得产出的比例, 研究目的是投入氮素不变或增施氮素能获得更高的 产出; 作物耐低氮性的研究目的是减少氮素的投入 能获得与正常施氮产出相近或降低较少 ${ }^{[9]}$ 。基于人 们已基本满足温饱, 急需解决环境污染和降低生产 成本, 对作物的耐低氮性研究已成为重点。

玉米生育后期(吐丝后)的物质积累与转运是籽 粒产量形成的物质基础, 籽粒中的氮素主要通过根 系吸收和营养器官的转运 ${ }^{[10]}$, 碳水化合物主要来源 于花后的光合生产和花前储存在营养器官中的碳水 化合物 ${ }^{[11]}$ 。非结构性碳水化合物 (non-structural carbohydrate, NSC, 可溶性糖和淀粉的总和)是作物 光合作用的产物, 其在营养器官的䛎藏量反映了植 株碳吸收(光合作用)与消耗间的平衡 ${ }^{[12-13]}$ 。氮肥是影 响作物碳、氮物质积累和转运的重要因素, 适宜的 氮肥用量使玉米在生育后期营养器官中氮素向籽粒 的转移和光合产物的积累增加, 进而提高了籽粒产 量 ${ }^{[14]}$ 。前人研究表明, 玉米品种生育后期的物质积 累和转运存在基因型差异 ${ }^{[7,15]}$ 。温立玉等 ${ }^{[16]}$ 研究表 明, 氮高效玉米品种 鲁单 $818^{\prime}$ 具有较氮低效品种 更高的花前氮转移效率和花后氮吸收能力。针对不 同氮转运效率玉米品种, 陈延玲 ${ }^{[17]}$ 发现“ 先玉 335' 较 郑单 958' 在同等氮水平下有相同的产量, 但是 却有较高的籽粒氮浓度, 主要因为它具有较高的营 养器官氮素转运效率以及成熟期较低的茎秆氮素残 留。茩建峰等 ${ }^{[14]}$ 研究表明, 碳氮代谢协调性较好的 品种在碳、氮的转运过程中, 能很好地协调光合产 物和氮素在籽粒灌浆和维持营养器官功能需求之间 的矛盾, 尤其是低氮水平下。作为我国玉米三大主 产区, 与北方地区不同, 西南丘陵玉米产区坡地比
重大、土地贫痊, 实际生产中, 农民常规施纯氮量高 达 $300 \mathrm{~kg} \mathrm{hm}^{-2}$, 且川中丘陵常年阴雨寡照, 昼夜温 差小, 玉米干物质转运、积累能力较北方更小 ${ }^{[18-19]}$ 。 有关氮肥水平对玉米干物质和氮素的积累与转运的 影响前人已有大量报道 ${ }^{[20-21]}$, 不同玉米品种生育后 期碳、氮代谢物质积累和转运对氮肥水平响应差异 及其对产量贡献程度也已见研究, 但多集中于北方 地区 ${ }^{[22-23]}$, 鲜见针对四川丘陵地区玉米品种耐低氮 能力与碳氮积累转运关系的研究。

本研究以不同耐低氮性玉米品种为材料, 通过 分析氮肥用量对不同耐低氮性玉米品种生育后期 碳、氮物质积累和转运效率对氮肥水平响应的差异 及其对籽粒产量的影响, 探明川中丘区与不同品种 相匹配的适宜施氮量和增产提效潜力, 为充分发挥 本区低氮高效型玉米品种的减氮提效作用, 实现产 量和 NUE 的协同提高提供理论依据。

\section{1 材料与方法}

\section{1 试验地概况}

于 2017-2019 年, 在四川省德阳市中江县合兴 乡新建村进行 (3038'59"N, 10453'36"E)。该地区属 于亚热带季风性湿润气候, 气象数据如图 1, 3 年生 育后期均无补充灌溉。2018 年 7 月大量降雨, 极大 影响了玉米吐丝至灌浆阶段的生长活动, 进而导致 本试验年际间的差异。供试土壤为紫色壤土。玉米 播前 0 20 cm 土壤基础地力数据如表 1。由于 2017 -2019 年玉米前茬作物不同(2017: 蔬菜; 2018: 羊 肚菌; 2019: 小麦), 导致 3 年地力存在差异。供试材 料为前期䇻选出的耐低氮品种 “正红 311, (Zhenghong 311，ZH311)和低氮敏感品种“先玉 508” (Xianyu 508, XY508) ${ }^{[6]}, 2$ 个品种生育期均为 $120 \mathrm{~d}$ 左右。

\section{2 试验设计}

本试验为 3 年定位试验, 采用二因素随机区组 试验设计, $\mathrm{A}$ 因素为不同耐低氮性玉米品种“正红 311 '和 ‘先玉 508', B 因素为氮肥(纯氮)用量, 所用氮 肥为尿素, 设 B0 $\left(0 \mathrm{~kg} \mathrm{hm}^{-2}\right) 、 B 1\left(150 \mathrm{~kg} \mathrm{hm}^{-2}\right) 、 B 2$ $\left(300 \mathrm{~kg} \mathrm{hm}^{-2}\right)$ 和 B3 $\left(450 \mathrm{~kg} \mathrm{hm}^{-2}\right) 4$ 个氮肥处理。共 8 个处理, 每处理 3 次重复, 共 24 个小区, 小区面积 $6.0 \mathrm{~m} \times 7.5 \mathrm{~m}$ 。

3 月下旬覆膜直播, 单株栽培, 宽窄行种植, 行距 为 $1.5 \mathrm{~m}+0.5 \mathrm{~m}$, 密度 52,500 株 $\mathrm{hm}^{-2} ; 50 \%$ 的氮肥做底 肥，50\%在大口期追施; 磷钾肥采用大田生产常规施 


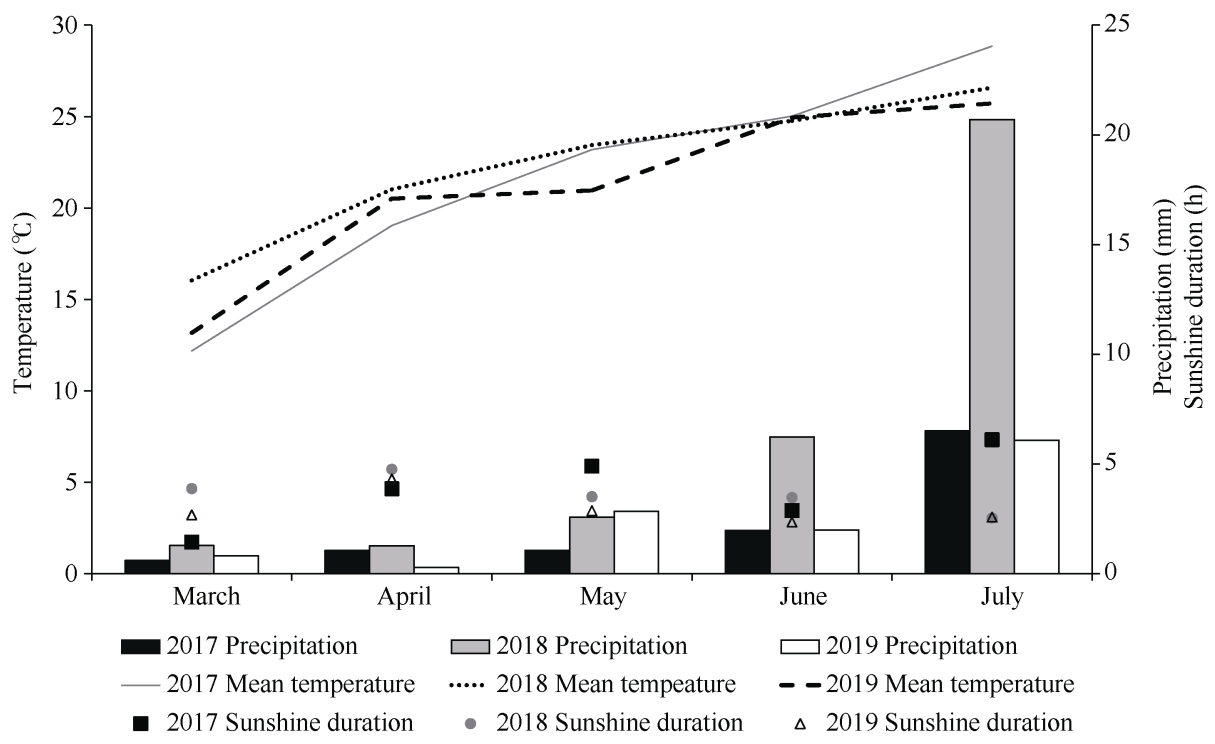

图 $1 \quad 2017-2019$ 年玉米全生育期(3 月至 7 月)气象数据

Fig. 1 Meteorological information of whole growth stages (from March to July) in maize from 2017 to 2019

表 $12017-2019$ 年玉米播前 $0 \sim 20 \mathrm{~cm}$ 土层基础地力

Table 1 Foundation soil capacity of 0-20 cm soil layer before maize sowing date from 2017 to 2019

\begin{tabular}{|c|c|c|c|c|c|c|}
\hline $\begin{array}{l}\text { 年份 } \\
\text { Year }\end{array}$ & $\begin{array}{c}\text { 全氮 } \\
\text { Total N } \\
\left(\mathrm{g} \mathrm{kg}^{-1}\right)\end{array}$ & $\begin{array}{c}\text { 有机质 } \\
\text { Organic matter } \\
\left(\mathrm{g} \mathrm{kg}^{-1}\right)\end{array}$ & $\begin{array}{c}\text { 碱解氮 } \\
\text { Alkali-hydrolysable N } \\
\left(\mathrm{mg} \mathrm{kg}^{-1}\right) \\
\end{array}$ & $\begin{array}{c}\text { 速效磷 } \\
\text { Available P } \\
\left(\mathrm{mg} \mathrm{kg}^{-1}\right) \\
\end{array}$ & $\begin{array}{c}\text { 速效钾 } \\
\text { Available K } \\
\left(\mathrm{mg} \mathrm{kg}^{-1}\right)\end{array}$ & $\mathrm{pH}$ \\
\hline 2017 & 1.55 & 10.32 & 110.60 & 11.16 & 131.91 & 5.78 \\
\hline 2018 & 1.51 & 11.13 & 108.53 & 15.43 & 105.27 & 5.90 \\
\hline 2019 & 1.23 & 10.66 & 48.22 & 12.84 & 122.07 & 5.46 \\
\hline
\end{tabular}

用量, 过磷酸钙 $600 \mathrm{~kg} \mathrm{hm}^{-2}$, 氯化钾 $150 \mathrm{~kg} \mathrm{hm}^{-2}$, 一次 性基施, 其他管理措施同当地生产实际, 7 月下旬收获。

\section{3 测定指标与方法}

1.3.1 千物质积累与转运量测定 2017-2019 年，在吐丝盛期，选择长势和吐丝期基本一致的植 株挂牌标记。由于玉米的茎叶干重仍会在吐丝期后 有一定增长, 直到吐丝 $7 \mathrm{~d}$ 后才发生物质转运，因此 于吐丝后 $7 \mathrm{~d}$ 和成熟期, 每个小区分别选取挂牌植 株 5 株, 将植株地上部分为茎鞘、叶片和穗(成熟期 分为籽粒、苞叶和穗轴), 在 $105^{\circ} \mathrm{C}$ 下杀青 $30 \mathrm{~min}$ 后 $75^{\circ} \mathrm{C}$ 烘至恒重后称重。用高速粉碎机将样品全株粉 碎备用, 用作全氮、可溶性糖和淀粉的测定。并计 算以下指标 ${ }^{[24]}$ :

花前干物质转运量 $(\mathrm{DRA})=$ 吐丝后 $7 \mathrm{~d}$ 茎叶干 重一成熟期茎叶干重

花前干物质转运率 $(\mathrm{DRR}, \%)=$ 花前物质转运 量/吐丝后 $7 \mathrm{~d}$ 茎叶干重 $\times 100$

花前干物质转运量对籽粒重的贡献率(CDRA, $\%)=$ 花前物质转运量/成熟期籽粒干重 $\times 100$
收获指数 $(\mathrm{HI})=$ 成熟期籽粒干重/成熟期植株 总干重

1.3.2 氮素积累与转运测定 2018-2019 年, 取 样方式同 1.3.1, 采用凯氏定氮法 ${ }^{[25]}$ 测定各器官全氮 含量。并计算以下指标 ${ }^{[26-27]}$ :

各器官氮素积累量 $=$ 各器官干物质重量 $\times$ 各器 官全氮百分含量

花前氮素转运量 $(N R A)=$ 吐丝后 $7 \mathrm{~d}$ 茎叶氮素 积累量-成熟期茎叶氮素积累量

花前氮素转运率 $(N R R ， \%)=$ 花前氮素转运量/ 吐丝后 $7 \mathrm{~d}$ 茎叶氮素积累量 $\times 100$

花前氮素转运量对籽粒氮素贡献率(CNRA，\%) $=$ 花前氮素转运量/成熟期籽粒氮素积累量 $\times 100$ (8)

氮素收获指数 $(\mathrm{NHI})=$ 成熟期籽粒氮素积累量/ 成熟期植株氮素积累量

\subsection{3 非结构性碳水化合物积累与转运测定}

2018-2019 年, 取样方式同 1.3.1, 采用葸酮-硫 酸比色法 ${ }^{[28]}$ 测定可溶性糖、淀粉含量, 可溶性糖和 淀粉含量即为非结构性碳水化合物 (NSC) 含量, 各 
器官 NSC 积累量 $=$ 各器官干物质重量 $\times$ 各器官 NSC 百分含量。并计算花前 NSC 转运量 (NSC translocation amount of pre-silking, NSCRA)和转运 率(NSC translocation rate of pre-silking, NSCRR)、花 前 NSC 转运量对籽粒贡献率(contribution rate of NSC translocation amount of pre-silking, CNSCRA)以 及收获指数(NSC harvest index, NSCHI), 公式同 1.3.2 氮素相关指标计算。

1.3.4 产量及产量构成因素 于成熟期每小区随 机连续取 20 穗, 调查百粒重。各小区实收计产, 折 算成 $14 \%$ 含水量的单位公顷产量，以实测产量除以 穗数和百粒重计算穗粒数。

\section{4 数据处理与统计}

采用 Microsoft Excel 2019 和 DPS 7.05 数据分析
软件整理与分析数据, 表 2 以三因素随机区组程序 进行方差分析，其余图和表以二因素随机区组程序 (氮肥 $\times$ 品种) LSD 法进行差异显著性检验。采用 Graphpad Prism 7 和 Microsoft Excel 2019 软件作图。

\section{2 结果与分析}

\section{1 关键指标方差分析结果}

方差分析表明(表2)，种植年份、玉米品种和氮 肥水平及三者的互作效应显著影响玉米的籽粒产量, 花前干物质、碳氮转运量及花后干物质、碳氮积累 量。其中，在品种和氮肥的互作效应上，籽粒产量以 及花前干物质、氮素和 $N S C$ 转运量达到极显著水平; 花后干物质、氮素和NSC积累量达显著水平，二者的 互作效应对物质转运的影响较物质积累更大。

表 2 年份、品种与氮肥水平对玉米产量和碳氮物质转运、积累量影响的方差分析

Table 2 Variance analysis of year, cultivar, and nitrogen application on grain yield, nitrogen and carbon translocation, and accumulation amount in maize

\begin{tabular}{|c|c|c|c|c|c|c|c|}
\hline $\begin{array}{c}\text { 变异来源 } \\
\text { Source of variation }\end{array}$ & $\begin{array}{c}\text { 籽粒产量 } \\
\text { Yield }\end{array}$ & $\begin{array}{c}\text { 花前干物质 } \\
\text { 转运量 } \\
\text { DRA }\end{array}$ & $\begin{array}{c}\text { 花后干物质 } \\
\text { 积累量 } \\
\text { DAA }\end{array}$ & $\begin{array}{c}\text { 花前氮素 } \\
\text { 转运量 } \\
\text { NRA }\end{array}$ & $\begin{array}{c}\text { 花后氮素 } \\
\text { 积累量 } \\
\text { NAA }\end{array}$ & $\begin{array}{c}\text { 花前 NSC } \\
\text { 转运量 } \\
\text { NSCRA }\end{array}$ & $\begin{array}{c}\text { 花后 NSC } \\
\text { 积累量 } \\
\text { NSCAA }\end{array}$ \\
\hline 年份 Year (Y) & $630.15^{* *}$ & $9.61^{* *}$ & $14.86^{* *}$ & $1913.22^{* *}$ & $46.96^{* *}$ & $18.99^{* *}$ & $40.73^{* *}$ \\
\hline 品种 Cultivar (C) & $111.32^{* *}$ & 0.37 & $124.41^{* *}$ & $502.68^{* *}$ & $18.95^{* *}$ & $127.54^{* *}$ & $89.09^{* *}$ \\
\hline 氮肥 Nitrogen $(\mathrm{N})$ & $165.15^{* *}$ & $107.02^{* *}$ & $180.00^{* *}$ & $27.18^{* *}$ & $152.56^{* *}$ & $174.83^{* *}$ & $154.60^{* *}$ \\
\hline $\mathrm{Y} \times \mathrm{C}$ & $14.72^{* *}$ & $57.38^{* *}$ & $5.01^{*}$ & $908.82^{* *}$ & $75.69^{* *}$ & 0.44 & $25.00^{* *}$ \\
\hline $\mathrm{Y} \times \mathrm{N}$ & $17.30^{* *}$ & $8.16^{* *}$ & $13.82^{* *}$ & $86.57^{* *}$ & $46.11^{* *}$ & $2.97^{*}$ & $11.42^{* *}$ \\
\hline $\mathrm{C} \times \mathrm{N}$ & $13.23^{* *}$ & $10.82^{* *}$ & $2.41^{*}$ & $5.97^{* *}$ & $4.18^{*}$ & $20.81^{* *}$ & $3.28^{*}$ \\
\hline $\mathrm{Y} \times \mathrm{C} \times \mathrm{N}$ & 1.05 & $12.17^{* *}$ & $4.14^{* *}$ & $12.90^{* *}$ & $19.08^{* *}$ & $8.21^{* *}$ & 2.14 \\
\hline
\end{tabular}

“和”*分别代表 $P<0.05$ 和 $P<0.01$ 显著水平。产量、干物质转运量和积累量为 2017-2019 年数据, 其余指标为 2018-2019 年数据。 Yield: grain yield; DRA: dry matter translocation amount of pre-silking; DAA: dry matter accumulation amount of post-silking; NRA: nitrogen translocation amount of pre-silking; NAA: nitrogen accumulation amount of post-silking; NSCRA: NSC translocation amount of pre-silking; NSCAA: NSC accumulation amount of post-silking. ${ }^{*}$ and ${ }^{* *}$ represent significant differences at $P<0.05$ and $P<0.01$, respectively. The data of yield, dry matter translocation and accumulation are from 2017 to 2019, and other indexes are from 2018 to 2019.

\section{2 不同施肥水平下玉米产量的品种间差异}

图 2 结果表明, 不同玉米品种间产量及其构成 因素对氮肥水平的响应存在差异。总的来说, 正红 311 籽粒产量, 尤其在低氮条件下 $\left(\leq 150 \mathrm{~kg} \mathrm{hm}^{-2}\right)$ 较 先玉 508 更具优势。2017-2019 年, $0 \mathrm{~kg} \mathrm{hm}^{-2}$ 氮处 理下，正红 311 籽粒产量较先玉 508 分别高 $31.98 \%$ 、 $26.40 \%$ 和 $14.02 \% ; 150 \mathrm{~kg} \mathrm{hm}^{-2}$ 氮处理下, 正红 311 籽粒产量较先玉 508 分别高 $27.06 \%$ 、16.94\%和 $24.10 \%$ 。除 2017 年外, 正红 311 和先玉 508 籽粒产 量在中高氮 $\left(300 \sim 450 \mathrm{~kg} \mathrm{hm}^{-2}\right)$ 差异不显著。低氮条件 下，品种间籽粒产量上的差异受各产量构成因素的 影响程度不同。除 2017 年外，穗粒数在正红 311 和 先玉 508 上的差异不显著; 而正红 311 的有效穗数
(除 2019 年)和百粒重(除 2018 年)在低氮条件下显著 高于先玉 508。正红 311 各产量构成因素在低氮处理 下要优于先玉 508, 但造成产量差异的主要因素受 年际间影响。

2.3 不同施肥水平下玉米干物质积累和转运的 品种间差异

氮肥用量对玉米植株干物质积累量(生物量)影 响显著(图 3), 但影响的程度在品种间存在一定差 异。随施氮量增加, 先玉 508 的干物质积累总量不 断增加, 正红 311 则先增后略降。各氮处理下正红 311 的干物质量均显著大于先玉 508 。从 2 个生育时 期(吐丝后 $7 \mathrm{~d}$ 和成熟期)干物质量平均结果来看, 2017 年正红 311 植株在 $0 、 150 、 300$ 和 $450 \mathrm{~kg} \mathrm{hm}^{-2}$ 

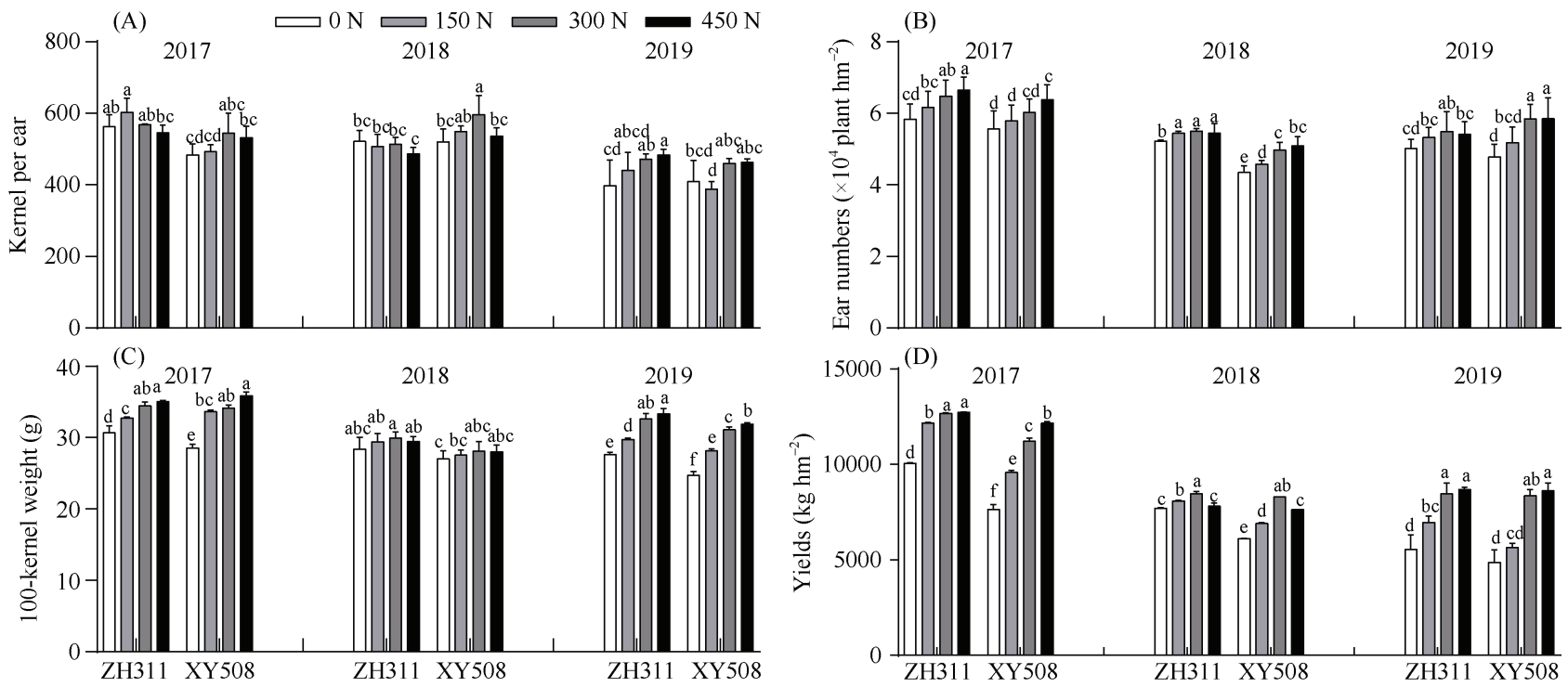

图 2 氮肥水平对耐低氮性玉米品种籽粒产量及其构成因素的影响

Fig. 2 Effects of $N$ level on grain yield and its components of maize with different low $\mathbf{N}$ tolerance

(A): 穗粒数; (B): 有效穗数; (C): 穗粒数; (D): 籽粒产量。多重比较仅在同一年份的 2 个品种间进行, 不同字母代表在 $P<0.05$ 水平 上差异显著。

ZH311: Zhenghong 311; XY508: Xianyu 508. (A): kernel per ear; (B): efficient ear numbers; (C): 100-kernel weight; (D): grain yield. Values followed by different lowercase letters in the same year and two cultivars indicate significant differences at $P<0.05$ by LSD test.
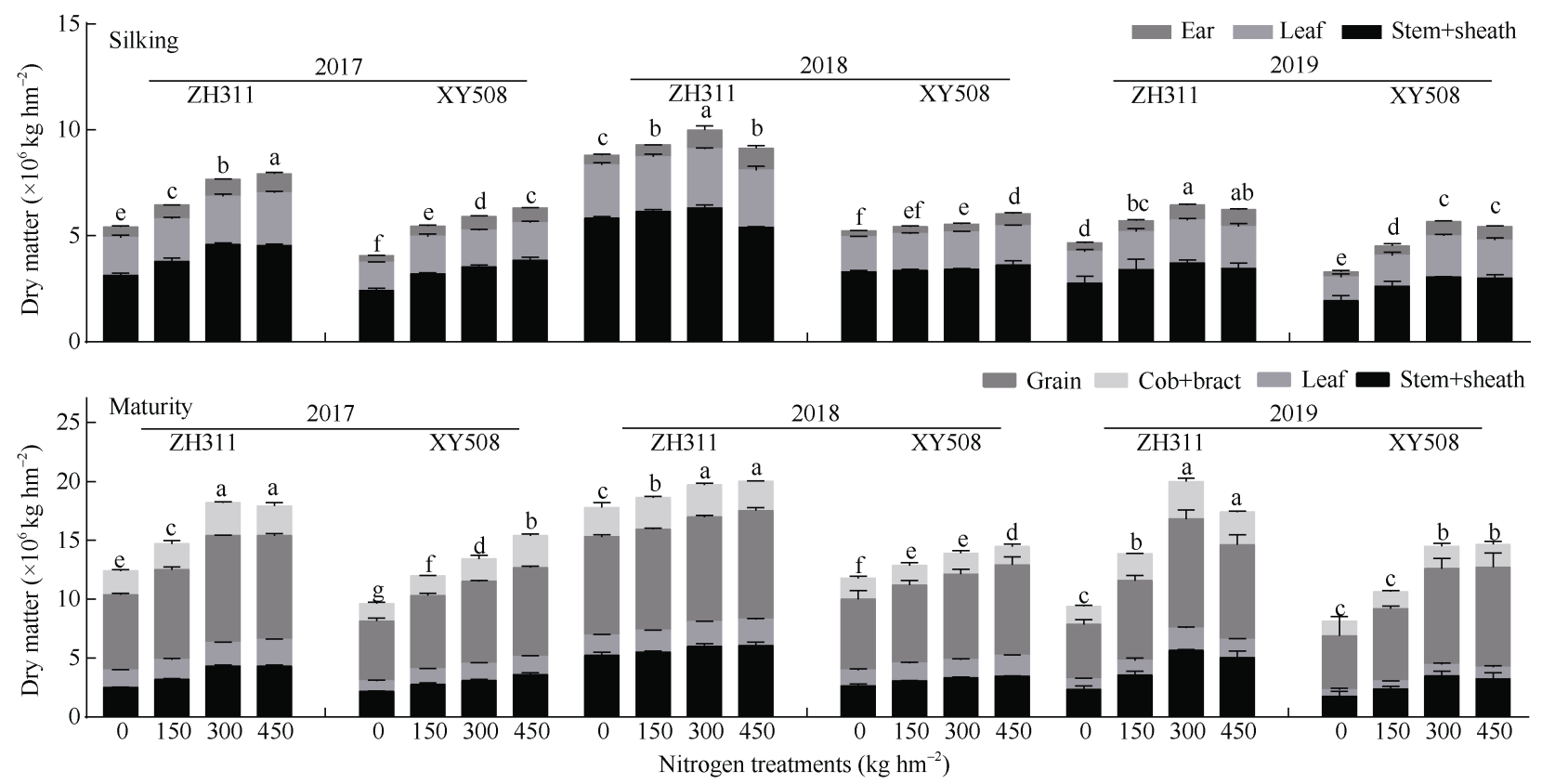

图 3 氮肥水平对不同耐低氮性玉米品种干物质积累的影响

Fig. 3 Effects of $\mathbf{N}$ level on dry matter accumulation of maize with different low $\mathbf{N}$ tolerance 多重比较仅在同一年份的 2 个品种间进行, 不同字母代表在 $P<0.05$ 水平上差异显著。

ZH311: Zhenghong 311; XY508: Xianyu 508. Values followed by lowercase letters in the same year and two cultivars indicate significant differences at $P<0.05$ by LSD test.

处理下的干物质积累量分别较先玉 508 高 $29.59 \%$ 、 $19.54 \% 、 35.44 \%$ 和 $18.16 \%, 2018$ 年分别高 $57.19 \%$ 、 $30.03 \% 、 39.03 \%$ 和 $45.91 \% ; 2019$ 年分别高 $26.86 \%$ 、 $27.81 \%$ 、30.46\%和 $17.20 \%$ 。
表 3 结果表明, 增施氮肥显著降低花前干物质 转运量(DRA)、转运率(DRR)及其对籽粒重的贡献率 (CDRA)和收获指数 $(\mathrm{HI})$, 提高植株花后物质积累量 (DAA) 及其对籽粒重的贡献率, DAA 对籽粒贡献率 
表 3 氮肥水平对不同耐低氮性玉米品种吐丝后干物质转运的影响

Table 3 Effects of $\mathbf{N}$ level on dry matter translocation of maize with different low $\mathbf{N}$ tolerance after silking stage

\begin{tabular}{|c|c|c|c|c|c|c|c|}
\hline $\begin{array}{l}\text { 年份 } \\
\text { Year }\end{array}$ & $\begin{array}{c}\text { 品种 } \\
\text { Cultivar }\end{array}$ & $\begin{array}{c}\text { 氮肥处理 } \\
\mathrm{N} \text { treatment } \\
\left(\mathrm{kg} \mathrm{hm}^{-2}\right)\end{array}$ & $\begin{array}{c}\text { 花前干物质 } \\
\text { 转运量 } \\
\text { DRA } \\
\left(\times 10^{6} \mathrm{~kg} \mathrm{hm}^{-2}\right) \\
\end{array}$ & $\begin{array}{c}\text { 花前干物质 } \\
\text { 转运率 } \\
\text { DRR } \\
(\%)\end{array}$ & $\begin{array}{c}\text { 花后干物质 } \\
\text { 积累量 } \\
\text { DAA } \\
\left(\times 10^{6} \mathrm{~kg} \mathrm{hm}^{-2}\right) \\
\end{array}$ & $\begin{array}{c}\text { 花前干物质转运对 } \\
\text { 籽粒重的贡献率 } \\
\text { CDRA } \\
(\%)\end{array}$ & $\begin{array}{c}\text { 收获指数 } \\
\text { HI }\end{array}$ \\
\hline \multirow[t]{8}{*}{2017} & ZH311 & 0 & $0.93 \mathrm{a}$ & $17.12 \mathrm{a}$ & $5.47 \mathrm{e}$ & $14.54 \mathrm{a}$ & $0.52 \mathrm{ab}$ \\
\hline & & 150 & $0.94 \mathrm{a}$ & $14.61 \mathrm{ab}$ & $6.69 \mathrm{c}$ & $12.34 \mathrm{ab}$ & $0.52 \mathrm{ab}$ \\
\hline & & 300 & $0.53 \mathrm{~cd}$ & $6.92 \mathrm{c}$ & $8.53 \mathrm{a}$ & $5.86 \mathrm{c}$ & $0.50 \mathrm{bc}$ \\
\hline & & 450 & $0.46 \mathrm{~d}$ & $5.77 \mathrm{c}$ & $8.37 \mathrm{a}$ & $5.19 \mathrm{c}$ & $0.49 \mathrm{c}$ \\
\hline & XY508 & 0 & $0.69 \mathrm{bc}$ & $17.09 \mathrm{a}$ & $4.39 \mathrm{f}$ & $13.69 \mathrm{a}$ & $0.52 \mathrm{ab}$ \\
\hline & & 150 & $0.76 \mathrm{ab}$ & $14.19 \mathrm{ab}$ & $5.40 \mathrm{e}$ & $12.31 \mathrm{ab}$ & $0.51 \mathrm{ab}$ \\
\hline & & 300 & $0.74 \mathrm{~b}$ & $12.36 \mathrm{~b}$ & $6.20 \mathrm{~d}$ & $10.67 \mathrm{~b}$ & $0.53 \mathrm{a}$ \\
\hline & & 450 & $0.47 \mathrm{~d}$ & $7.46 \mathrm{c}$ & $7.07 \mathrm{~b}$ & $6.25 \mathrm{c}$ & $0.49 \mathrm{c}$ \\
\hline \multirow[t]{8}{*}{2018} & ZH311 & 0 & $1.35 \mathrm{a}$ & $15.43 \mathrm{ab}$ & $6.97 \mathrm{c}$ & $16.23 \mathrm{a}$ & $0.47 \mathrm{ab}$ \\
\hline & & 150 & $1.33 \mathrm{a}$ & $14.44 \mathrm{~b}$ & $7.21 \mathrm{c}$ & $15.59 \mathrm{a}$ & $0.46 \mathrm{~b}$ \\
\hline & & 300 & $0.99 \mathrm{~b}$ & $9.96 \mathrm{c}$ & $7.87 \mathrm{~b}$ & $11.14 \mathrm{~b}$ & $0.45 \mathrm{~b}$ \\
\hline & & 450 & $0.00 \mathrm{e}$ & $0.00 \mathrm{e}$ & $9.21 \mathrm{a}$ & $0.00 \mathrm{e}$ & $0.46 \mathrm{~b}$ \\
\hline & XY508 & 0 & $0.95 \mathrm{~b}$ & $18.32 \mathrm{a}$ & $5.04 \mathrm{e}$ & $15.23 \mathrm{a}$ & $0.51 \mathrm{ab}$ \\
\hline & & 150 & $0.52 \mathrm{c}$ & $9.76 \mathrm{c}$ & $6.11 \mathrm{~d}$ & $7.87 \mathrm{bc}$ & $0.46 \mathrm{~b}$ \\
\hline & & 300 & $0.31 \mathrm{~cd}$ & $5.62 \mathrm{~d}$ & $6.95 \mathrm{c}$ & $4.25 \mathrm{~cd}$ & $0.48 \mathrm{ab}$ \\
\hline & & 450 & $0.25 \mathrm{~d}$ & $4.06 \mathrm{~d}$ & $7.43 \mathrm{bc}$ & $3.15 \mathrm{de}$ & $0.53 \mathrm{a}$ \\
\hline \multirow[t]{8}{*}{2019} & ZH311 & 0 & $1.03 \mathrm{a}$ & $22.07 \mathrm{~b}$ & $3.59 \mathrm{e}$ & $22.39 \mathrm{a}$ & $0.49 \mathrm{c}$ \\
\hline & & 150 & $0.41 \mathrm{c}$ & $7.09 \mathrm{~d}$ & $6.36 \mathrm{c}$ & $6.00 \mathrm{~b}$ & $0.49 \mathrm{c}$ \\
\hline & & 300 & $0.00 \mathrm{~d}$ & $0.00 \mathrm{e}$ & $9.23 \mathrm{a}$ & $0.00 \mathrm{c}$ & $0.46 \mathrm{~d}$ \\
\hline & & 450 & $0.00 \mathrm{~d}$ & $0.00 \mathrm{e}$ & $8.00 \mathrm{~b}$ & $0.00 \mathrm{c}$ & $0.46 \mathrm{~d}$ \\
\hline & XY508 & 0 & $0.92 \mathrm{ab}$ & $28.26 \mathrm{a}$ & $3.66 \mathrm{e}$ & $21.64 \mathrm{a}$ & $0.56 \mathrm{~b}$ \\
\hline & & 150 & $1.03 \mathrm{a}$ & $22.69 \mathrm{~b}$ & $7.38 \mathrm{~b}$ & $16.76 \mathrm{a}$ & $0.58 \mathrm{ab}$ \\
\hline & & 300 & $0.74 \mathrm{~b}$ & $13.14 \mathrm{c}$ & $8.12 \mathrm{~b}$ & $9.39 \mathrm{~b}$ & $0.56 \mathrm{~b}$ \\
\hline & & 450 & $0.35 \mathrm{c}$ & $6.42 \mathrm{~d}$ & $7.25 \mathrm{~b}$ & $4.17 \mathrm{bc}$ & $0.58 \mathrm{a}$ \\
\hline
\end{tabular}

多重比较仅在同一列同一年份的 2 个品种间进行, 不同字母代表在 $P<0.05$ 水平上差异显著。“和”*分别代表 $P<0.05$ 和 $P<0.01$ 显著 水平。

ZH311: Zhenghong 311, XY 508: Xianyu 508. DRA: dry matter translocation amount of pre-silking; DRR: dry matter translocation rate of pre-silking; DAA: dry matter accumulation amount of post-silking; CDRA: contribution rate of dry matter translocation amount of pre-silking; HI: harvest index. Values followed by the same letter within a column in the same year and two cultivars are not significantly different at $P<0.05$ by LSD test. ${ }^{*}$ and ${ }^{* *}$ represent significant at $P<0.05$ and $P<0.01$, respectively.

大于 DRA。低氮处理 $\left(0 \sim 150 \mathrm{~kg} \mathrm{hm}^{-2}\right)$, 正红 311 的 DRA 和 CDRA 较先玉 508 更高或接近，中高氮(300 $450 \mathrm{~kg} \mathrm{hm}^{-2}$ )下则相反, 其 DRA 和 CDRA 较先玉 508 更低, 尤其 2019 年, 正红 311 在 $300 \mathrm{~kg} \mathrm{hm}^{-2}$ 和 $450 \mathrm{~kg} \mathrm{hm}^{-2}$ 干物质没有转运。

2.4 不同施肥水平下玉米非结构性碳水化合物 积累和转运的品种间差异

由图 4 可知, 各氮处理下, 正红 311 的 NSC 含 量均显著大于先玉 508 。从 2 个生育时期 NSC 积累 量平均结果来看, 2018 年正红 311 在 $0 、 150 、 300$
和 $450 \mathrm{~kg} \mathrm{hm}^{-2}$ 处理下, 植株 NSC 较先玉 508 分别高 $56.59 \% 、 25.46 \% 、 31.61 \%$ 和 $24.31 \% ; 2019$ 年较先玉 508 分别高 $22.38 \% 、 17.20 \% 、 25.74 \%$ 和 $1.54 \%$ 。品 种间 2 年的差异均在 $0 \mathrm{~kg} \mathrm{hm}^{-2}$ 处理下最大, 2018 年 的差异大于 2019 年。

由表 4 可知, 与干物质转运相似, 增施氮肥显 著降低吐丝后植株 NSC 转运量(NSCRA)、转运率 (NSCRR)及其对籽粒 NSC (CNSCRA)的贡献率和 NSC 收获指数(NSCHI), 提高植株花后 NSC 积累量 (NSCAA)及其对籽粒 NSC 的贡献率。正红 311 的 

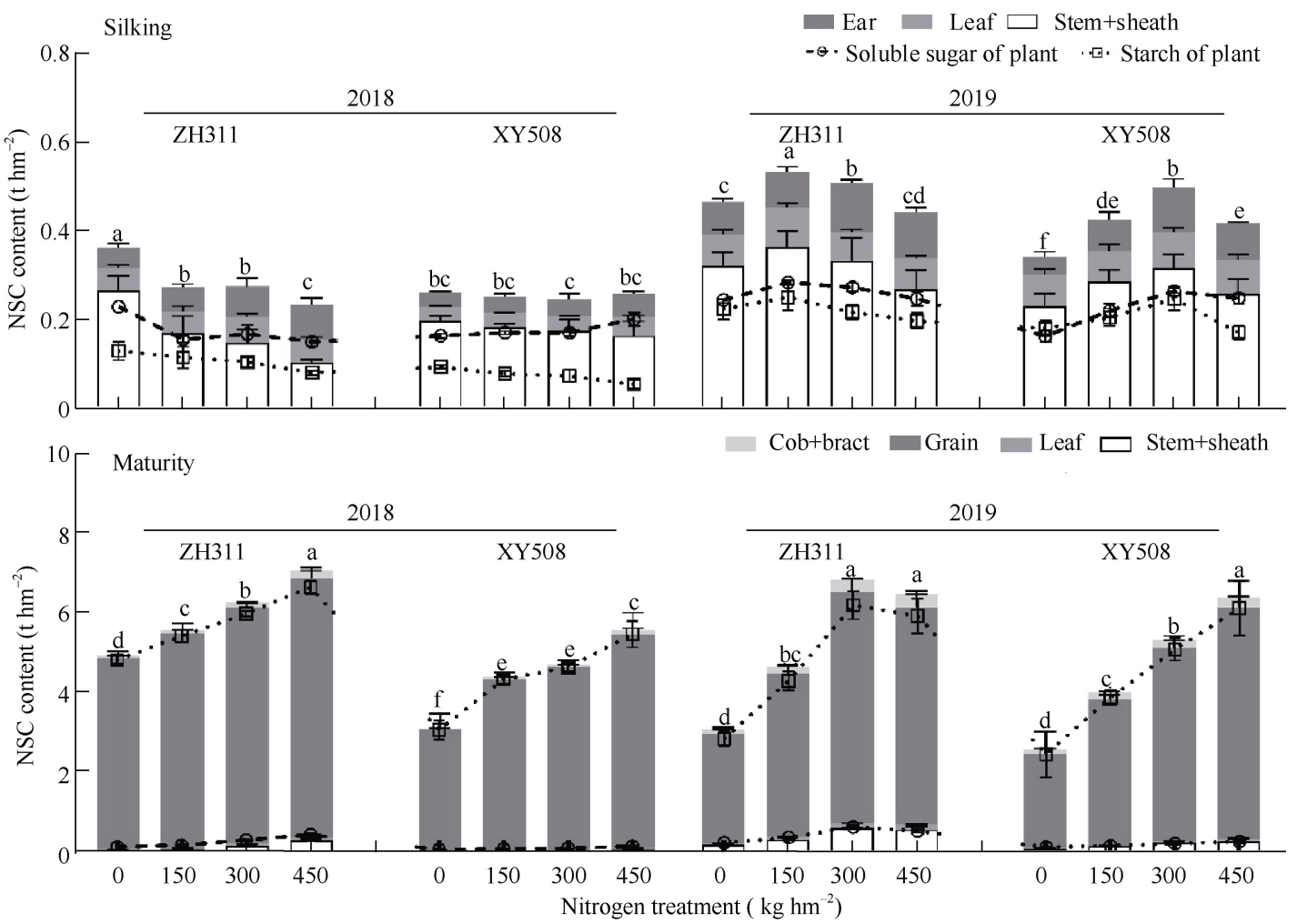

图 4 氮肥水平对不同耐低氮性玉米品种非结构性碳水化合物(NSC)积累的影响

Fig. 4 Effects of $\mathrm{N}$ level on non-structural carbohydrate (NSC) accumulation of maize with different low $\mathrm{N}$ tolerance 多重比较仅在同一年份的 2 个品种间进行, 不同字母代表在 $P<0.05$ 水平上差异显著。

ZH311: Zhenghong 311; XY508: Xianyu 508. Values followed in the same year and two cultivars are not significantly different at $P<0.05$ by the LSD test.

NSCRA、NSCRR 和 CNSCRA 较先玉 508 更低。2018 年, 正红 $311 \mathrm{NSCRR}$ 在 $0 \sim 450 \mathrm{~kg} \mathrm{hm}^{-2}$ 氮处理下分别 较先玉 508 低 $19.63 \% 、 46.58 \% 、 88.85 \%$ 和 $100.00 \%$, 2019 年分别低 $33.54 \% 、 66.02 \% 、 100.00 \%$ 和 $100.00 \%$; 正红 311 的 CNSCRA 在 $0 \sim 450 \mathrm{~kg} \mathrm{hm}^{-2}$ 氮处理下较 先玉 508 分别低(2018 年) $29.44 \% 、 45.24 \% 、 92.18 \%$ 和 $100.00 \%, 2019$ 年分别低 $32.20 \% 、 60.99 \% 、 100.00 \%$ 和 $100.00 \%$ ，二者差异随施氮量的减少而减小。与花 前 NSC 转运相反, 正红 311 的 NSCAA 及其对籽粒 NSC 的贡献较先玉 508 高, 二者差距随施氮量的减 少增大。

2.5 不同施肥水平下玉米氮素积累和转运的品 种间差异

氮水平对玉米氮积累量同样存在品种差异 (图 5)。各氮处理下，正红 311 的氮积累量均显著大 于先玉 508。从 2 个生育时期氮素积累量平均结果 来看, 正红 311 植株在 $0 、 150 、 300$ 和 $450 \mathrm{~kg} \mathrm{hm}^{-2}$ 处理下，氮积累量在 2018 年较先玉 508 高 44.16\%、 $32.18 \%$ 、 $49.22 \%$ 和 $43.67 \%, 2019$ 年高 $10.30 \%$ 、 $27.51 \% 、 58.84 \%$ 和 $23.09 \%, 2018$ 年的差异较 2019
年大。花前和花后氮素积累量在成熟期植株氮素积 累量的占比存在年际差异, 2018 年, 正红 311 在 0 450 kg hm 氮肥水平下花前氮素积累量分别占成 熟期氮素积累量的 $79.64 \% 、 78.02 \% 、 82.51 \%$ 和 $67.12 \%, 2019$ 年花前氮素积累量分别占 $69.28 \%$ 、 $46.06 \%$ 、4 $40.97 \%$ 和 $50.93 \% ; 2018$ 年，先玉 508 在各 氮水平下花前氮素积累量分别占成熟期氮素积累量 的 $71.74 \% 、 59.78 \% 、 58.70 \%$ 和 $58.47 \%$ ，而 2019 年 分别占 $64.32 \% 、 51.03 \% 、 51.97 \%$ 和 $49.85 \%$ 。总的 来说, 2018 年花前氮素积累率较 2019 年大, 正红 311 花前氮素积累率较先玉 508 高。

如表 5 所示, 随着施氮量增加, 植株的氮素转 运率 $(\mathrm{NRR})$ 及其对籽粒氮素(CNRA) 呈下降趋势, 花 后氮素积累量(NAA)及其对籽粒氮素的贡献率呈增 加趋势, 高氮会降低氮收获指数 $(\mathrm{NHI})$ 。各指标年际 差异较大, 品种间的氮素转运、积累对氮水平响应 程度也不同。2018 年, 正红 311 的 NRA、NRR 和 CNRA 均显著大于先玉 508, NAA 及其对籽粒氮素 的贡献则更小。正红 311 的 NRA 在 $0 \sim 450 \mathrm{~kg} \mathrm{hm}^{-2}$ 处理下分别较先玉 508 高 $90.55 \% 、 119.20 \% 、 150.88 \%$ 
表 4 氮肥水平对不同耐低氮性玉米吐丝后非结构性碳水化合物转运的影响

Table 4 Effects of $\mathrm{N}$ level on non-structural carbohydrate (NSC) translocation of maize with different low N tolerance after silking stage

\begin{tabular}{|c|c|c|c|c|c|c|c|}
\hline $\begin{array}{l}\text { 年份 } \\
\text { Year }\end{array}$ & $\begin{array}{c}\text { 品种 } \\
\text { Cultivar }\end{array}$ & $\begin{array}{c}\text { 氮肥处理 } \\
\mathrm{N} \text { treatment } \\
\left(\mathrm{kg} \mathrm{hm}^{-2}\right) \\
\end{array}$ & $\begin{array}{c}\text { 花前 NSC 转运量 } \\
\text { NSCRA } \\
\left(\mathrm{t} \mathrm{hm}^{-2}\right)\end{array}$ & $\begin{array}{c}\text { 花前 NSC 转运率 } \\
\text { NSCRR } \\
(\%)\end{array}$ & $\begin{array}{c}\text { 花后 NSC 积累量 } \\
\text { NSCAA } \\
\left(\mathrm{t} \mathrm{hm}^{-2}\right)\end{array}$ & $\begin{array}{c}\text { 花前 NSC 转运对 } \\
\text { 籽粒 NSC 贡献率 } \\
\text { CNSCRA (\%) }\end{array}$ & $\begin{array}{c}\mathrm{NSC} \\
\text { 收获指数 } \\
\mathrm{NSCHI} \\
\end{array}$ \\
\hline \multirow[t]{8}{*}{2018} & ZH311 & 0 & $0.24 \mathrm{a}$ & $75.70 \mathrm{~b}$ & $4.55 \mathrm{~d}$ & $5.01 \mathrm{~b}$ & $0.97 \mathrm{~b}$ \\
\hline & & 150 & $0.11 \mathrm{~cd}$ & $50.32 \mathrm{c}$ & $5.25 \mathrm{c}$ & $2.07 \mathrm{c}$ & $0.96 \mathrm{c}$ \\
\hline & & 300 & $0.01 \mathrm{e}$ & $10.50 \mathrm{~d}$ & $5.90 \mathrm{~b}$ & $0.33 \mathrm{~d}$ & $0.94 \mathrm{e}$ \\
\hline & & 450 & $0.00 \mathrm{e}$ & $0.00 \mathrm{e}$ & $6.49 \mathrm{a}$ & $0.00 \mathrm{~d}$ & $0.92 \mathrm{f}$ \\
\hline & XY508 & 0 & $0.21 \mathrm{a}$ & $94.19 \mathrm{a}$ & $2.83 \mathrm{f}$ & $7.10 \mathrm{a}$ & $0.98 \mathrm{a}$ \\
\hline & & 150 & $0.16 \mathrm{~b}$ & $75.32 \mathrm{~b}$ & $4.11 \mathrm{e}$ & $3.78 \mathrm{~b}$ & $0.97 \mathrm{~b}$ \\
\hline & & 300 & $0.15 \mathrm{bc}$ & $70.64 \mathrm{~b}$ & $4.42 \mathrm{~d}$ & $4.22 \mathrm{~b}$ & $0.97 \mathrm{~b}$ \\
\hline & & 450 & $0.10 \mathrm{~d}$ & $46.94 \mathrm{c}$ & $5.24 \mathrm{c}$ & $1.81 \mathrm{c}$ & $0.95 \mathrm{~d}$ \\
\hline \multirow[t]{8}{*}{2019} & ZH311 & 0 & $0.17 \mathrm{a}$ & $44.03 \mathrm{c}$ & $2.55 \mathrm{~d}$ & $6.40 \mathrm{~b}$ & $0.89 \mathrm{~b}$ \\
\hline & & 150 & $0.08 \mathrm{c}$ & $18.34 \mathrm{e}$ & $4.00 \mathrm{c}$ & $2.04 \mathrm{~cd}$ & $0.88 \mathrm{~b}$ \\
\hline & & 300 & $0.00 \mathrm{~d}$ & $0.00 \mathrm{f}$ & $5.79 \mathrm{a}$ & $0.00 \mathrm{~d}$ & $0.85 \mathrm{c}$ \\
\hline & & 450 & $0.00 \mathrm{~d}$ & $0.00 \mathrm{f}$ & $5.44 \mathrm{a}$ & $0.00 \mathrm{~d}$ & $0.85 \mathrm{c}$ \\
\hline & XY508 & 0 & $0.20 \mathrm{a}$ & $66.25 \mathrm{a}$ & $2.13 \mathrm{~d}$ & $9.44 \mathrm{a}$ & $0.91 \mathrm{a}$ \\
\hline & & 150 & $0.19 \mathrm{a}$ & $53.97 \mathrm{~b}$ & $3.48 \mathrm{c}$ & $5.23 \mathrm{~b}$ & $0.92 \mathrm{a}$ \\
\hline & & 300 & $0.05 \mathrm{c}$ & $32.73 \mathrm{~d}$ & $4.70 \mathrm{~b}$ & $4.18 \mathrm{bc}$ & $0.91 \mathrm{a}$ \\
\hline & & 450 & $0.01 \mathrm{~d}$ & $3.94 \mathrm{f}$ & $5.78 \mathrm{a}$ & $0.25 \mathrm{~d}$ & $0.91 \mathrm{a}$ \\
\hline
\end{tabular}

多重比较仅在同一列同一年份的 2 个品种间进行, 不同字母代表在 $P<0.05$ 水平上差异显著。“和”“分别代表 $P<0.05$ 和 $P<0.01$ 显著 水平。

ZH311: Zhenghong 311; XY508: Xianyu 508. NSCRA: NSC translocation amount of pre-silking; NSCRR: NSC translocation rate of pre-silking; NSCAA: NSC accumulation amount of post-silking; CNSCRA: Contribution rate of NSC translocation amount of pre-silking; NSCHI: NSC harvest index. Values followed by the same letter within a column in the same year and two cultivars are not significantly different at $P<0.05$ by LSD test. ${ }^{*}$ and ${ }^{* *}$ represent significant differences at $P<0.05$ and $P<0.01$, respectively.

和 $130.66 \%$; NRR 分别高 $25.16 \% 、 40.69 \% 、 43.61 \%$ 和 $52.69 \%$; CNRA 则分别高 $24.46 \% 、 74.34 \% 、 87.41 \%$ 和 $54.68 \%$ 。正红 311 的 NAA 在 $0 \sim 450 \mathrm{~kg} \mathrm{hm}^{-2}$ 处理 下较先玉 508 分别低- $0.77 \% 、 31.98 \% 、 33.12 \%$ 和 $-11.50 \%$ 。与 2018 年不同, 2019 年, 正红 311 的 NRA、 NRR 和 CNRA 较先玉 508 更小。0 450 kg hm${ }^{-2}$ 处理 下, 正红 311 的 NRA 较先玉 508 分别低 $14.50 \%$ 、 $16.09 \% 、 52.09 \%$ 和 $22.62 \%$; NRR 分别低 $22.29 \%$ 、 $30.23 \% 、 66.84 \%$ 和 $41.89 \%$; CNRA 分别低 $18.94 \%$ 、 $31.30 \% 、 66.91 \%$ 和 $31.11 \%$ 。2 个品种间 NAA 及其对 籽粒氮素贡献的差异 2 年表现相同规律。0 450 $\mathrm{kg} \mathrm{hm}^{-2}$ 氮处理下, 正红 311 的NAA 较先玉 508 分别高 $32.53 \%$ 、 $41.20 \% 、 73.99 \%$ 和 $23.20 \%$ 。总的来说, 正红 311 花后氮 素的积累, 尤其是低氮条件下 $\left(\leq 150 \mathrm{~kg} \mathrm{hm}^{-2}\right)$, 比先玉 508 的大。

\section{6 物质积累、转运与籽粒产量的关系} 不同品种物质积累、转运与籽粒产量的关系见 表 6。对正红 311 而言, 其籽粒产量、有效穗数与花
后干物质、 NSC 积累量关系密切, 其关系均达显著 或极显著水平; 穗粒数和氮素转运量与 NSC 积累量 密切相关; 百粒重的形成则与干物质和 NSC 的转运以 及氮的积累量有显著关系; 干物质的花前转运量与氮 积累量和 NSC 转运量相关系数达显著、极显著水平, 而花后干物质积累量与 NSC 的积累极显著正相关。

与正红 311 不同的是, 先玉 508 的产量除与花 后干物质、NSC 积累量密切相关外, 还与花前干物 质和 NSC 的转运量密切相关; 有效穗数受氮素转 运、积累量的影响也达到显著水平; 穗粒数与干物 质转运呈显著负相关, 和其他指标关系不大; 百粒 重除了和干物质转运量关系不大，和各其他物质、 转运积累量均显著、极显著正相关; 干物质转运量 与氮素的积累、转运及 NSC 的转运的关系不密切, 与其余物质积累量呈显著或极显著负相关，干物质 积累量与 NSC 的转运呈负显著水平; 氮素转运和积 累极显著正相关; NSC 的转运量与其积累量呈显著 负相关。 

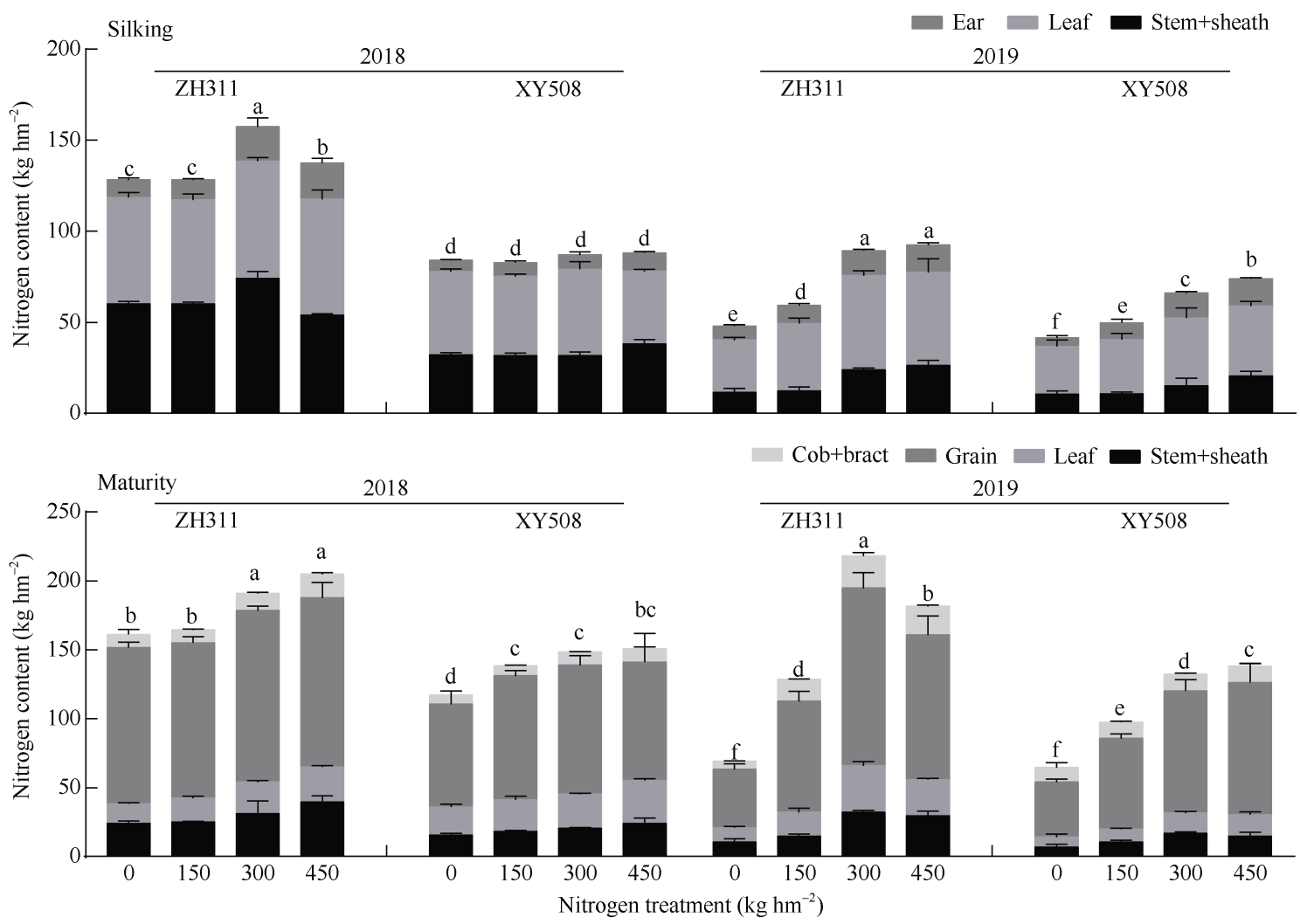

图 5 氮肥水平对不同耐低氮性玉米品种氮素积累的影响

Fig. 5 Effect of $\mathbf{N}$ level on $\mathbf{N}$ accumulation with different low $\mathbf{N}$ tolerance in maize 多重比较仅在同一年份的 2 个品种间进行, 不同字母代表在 $P<0.05$ 水平上差异显著。

ZH311: Zhenghong 311; XY508: Xianyu 508. Values followed by different lowercase letters in the same year and two cultivars indicate significant differences at $P<0.05$ by LSD test.

\section{3 讨论}

\section{1 增施氮肥促进花后碳氮物质积累，降低花前 物质转运效率}

作物养分吸收、积累是干物质形成和累积的基 础, 也是产量形成的前提 ${ }^{[29]}$ 。在生产成本渐高及环 境污染日益严重的形势下，如何在保证产量的同 时, 进行氮肥优化管理, 实现较高的氮肥利用率, 是玉米生产中一个亟待解决的问题 ${ }^{[4,30]}$ 。众多研究 表明 ${ }^{[27,31]}$, 在受到缺氮胁迫时, 营养器官中氮、碳向 籽粒转移的比例明显增加。缺氮胁迫时, 土壤中的 氮无法满足籽粒灌浆需要, 茎叶中的氮素转移量便 增加, 如果氮转移过多, 则会削弱光合活性, 减少 同化物合成 ${ }^{[10,32]}$ 。吐丝前的光合产物在营养器官中 以非结构性碳水化合物的形式咜存 ${ }^{[5,33]}$, 在花后作 为重要的“源”，为籽粒灌浆提供物质基础 ${ }^{[34]}$ 。

本研究表明, 增施氮肥使玉米植株的干物质、 氮素积累量增多; 花前干物质和 NSC 的转运量、转 运率及其对籽粒的贡献率随施氮量显著降低, 花后
积累量及其对籽粒的贡献率则随氮肥施用量增加; 在土壤供氮不足时, 氮素的转移量和比例较氮素充 足(过量)供应时也更大, 这与前人结果相似 ${ }^{[22,24]}$ 。无 论是籽粒干重还是 NSC, 均以花后物质积累对籽粒 贡献更大, 且花后贡献率随氮肥增施逐渐增高。尽 管低氮环境下, 玉米植株有较高的花前碳水化合物 积累量及氮转运量以弥补产量损失, 但合理的氮肥 用量能够维持植株碳氮代谢的平衡, 进而影响玉米 生育后期营养器官碳、氮素的转运及光合产物的积 累, 促进碳、氮同化物向籽粒的供应, 从而提高籽粒 产量 ${ }^{[22,35]}$ 。

3.2 不同耐低氮性玉米品种生育后期干物质积 累与转运特性存在一定差异

大量研究表明，同一作物不同品种间的耐低氮 能力和氮效率存在一定差异 ${ }^{[5-7]}$ 。作物的耐低氮能力, 一般用低氮与正常氮评价指标的相对值表示, 是品 种之间指标相对值的比较, 据此可以分为耐低氮 型、中间型、低氮敏感型 3 类 $^{[8,36]}$ 。我们在前期研究 中发现, 耐低氮品种正红 311 较低氮敏感品种先玉 
表 5 氮肥水平对不同耐低氮性玉米品种氮素转运的影响

Table 5 Effects of $N$ level on $N$ translocation of maize with different low $N$ tolerance after silking

\begin{tabular}{|c|c|c|c|c|c|c|c|}
\hline $\begin{array}{l}\text { 年份 } \\
\text { Year }\end{array}$ & $\begin{array}{c}\text { 品种 } \\
\text { Cultivar }\end{array}$ & $\begin{array}{c}\text { 氮肥处理 } \\
\mathrm{N} \text { treatment } \\
\left(\mathrm{kg} \mathrm{hm}^{-2}\right)\end{array}$ & $\begin{array}{c}\text { 花前氮素转运量 } \\
\text { NRA } \\
\left(\mathrm{kg} \mathrm{hm}^{-2}\right)\end{array}$ & $\begin{array}{c}\text { 花前氮素转运率 } \\
\text { NRR } \\
(\%)\end{array}$ & $\begin{array}{c}\text { 花后氮素积累量 } \\
\text { NAA } \\
\left(\mathrm{kg} \mathrm{hm}^{-2}\right)\end{array}$ & $\begin{array}{c}\text { 花前氮素转运对 } \\
\text { 籽粒氮素的贡献 } \\
\text { CNRA }(\%)\end{array}$ & $\begin{array}{c}\text { 氮素收获 } \\
\text { 指数 } \\
\text { NHI }\end{array}$ \\
\hline \multirow[t]{8}{*}{2018} & ZH311 & 0 & $80.14 \mathrm{a}$ & $67.63 \mathrm{a}$ & $33.01 \mathrm{c}$ & $70.85 \mathrm{a}$ & $0.70 \mathrm{a}$ \\
\hline & & 150 & $74.92 \mathrm{~b}$ & $63.92 \mathrm{~b}$ & $37.91 \mathrm{c}$ & $66.42 \mathrm{a}$ & $0.69 \mathrm{ab}$ \\
\hline & & 300 & $84.54 \mathrm{a}$ & $61.20 \mathrm{~b}$ & $40.06 \mathrm{c}$ & $67.93 \mathrm{a}$ & $0.65 \mathrm{bc}$ \\
\hline & & 450 & $52.60 \mathrm{c}$ & $44.81 \mathrm{~d}$ & $70.23 \mathrm{a}$ & $43.09 \mathrm{c}$ & $0.60 \mathrm{de}$ \\
\hline & XY508 & 0 & $42.06 \mathrm{~d}$ & $54.03 \mathrm{c}$ & $32.75 \mathrm{c}$ & $56.92 \mathrm{~b}$ & $0.64 \mathrm{c}$ \\
\hline & & 150 & $34.18 \mathrm{e}$ & $45.43 \mathrm{~d}$ & $55.73 \mathrm{~b}$ & $38.10 \mathrm{~cd}$ & $0.65 \mathrm{c}$ \\
\hline & & 300 & $33.70 \mathrm{e}$ & $42.61 \mathrm{~d}$ & $59.89 \mathrm{ab}$ & $36.24 \mathrm{~d}$ & $0.63 \mathrm{~cd}$ \\
\hline & & 450 & $22.80 \mathrm{f}$ & $29.34 \mathrm{e}$ & $62.98 \mathrm{ab}$ & $27.86 \mathrm{e}$ & $0.57 \mathrm{e}$ \\
\hline \multirow[t]{8}{*}{2019} & ZH311 & 0 & $19.23 \mathrm{bc}$ & $48.01 \mathrm{~b}$ & $22.99 \mathrm{e}$ & $45.75 \mathrm{~b}$ & $0.61 \mathrm{bc}$ \\
\hline & & 150 & $17.39 \mathrm{c}$ & $35.49 \mathrm{c}$ & $63.40 \mathrm{c}$ & $21.65 \mathrm{~d}$ & $0.63 \mathrm{abc}$ \\
\hline & & 300 & $9.63 \mathrm{~d}$ & $12.76 \mathrm{e}$ & $119.36 \mathrm{a}$ & $7.51 \mathrm{e}$ & $0.59 \mathrm{c}$ \\
\hline & & 450 & $21.82 \mathrm{~b}$ & $27.86 \mathrm{~d}$ & $83.40 \mathrm{~b}$ & $20.51 \mathrm{~d}$ & $0.58 \mathrm{c}$ \\
\hline & XY508 & 0 & $22.49 \mathrm{~b}$ & $61.79 \mathrm{a}$ & $17.35 \mathrm{e}$ & $56.44 \mathrm{a}$ & $0.62 \mathrm{abc}$ \\
\hline & & 150 & $20.73 \mathrm{bc}$ & $50.87 \mathrm{~b}$ & $44.90 \mathrm{~d}$ & $31.51 \mathrm{c}$ & $0.67 \mathrm{ab}$ \\
\hline & & 300 & $20.09 \mathrm{bc}$ & $38.47 \mathrm{c}$ & $68.60 \mathrm{c}$ & $22.71 \mathrm{~d}$ & $0.70 \mathrm{a}$ \\
\hline & & 450 & $28.19 \mathrm{a}$ & $47.94 \mathrm{~b}$ & $67.70 \mathrm{c}$ & $29.77 \mathrm{c}$ & $0.65 \mathrm{abc}$ \\
\hline
\end{tabular}

多重比较仅在同一列同一年份的 2 个品种间进行, 不同字母代表在 $P<0.05$ 水平上差异显著。“和”“分别代表 $P<0.05$ 和 $P<0.01$ 显著 水平。

ZH311: Zhenghong 311; XY508: Xianyu 508. NRA: nitrogen translocation amount of pre-silking; NRR: nitrogen translocation rate of pre-silking; NAA: nitrogen accumulation amount of post-silking; CNRA: Contribution rate of nitrogen translocation amount of pre-silking; NHI: nitrogen harvest index. Values followed by the same letter within a column in the same year and two cultivars are not significantly different at $P<0.05$ as determined by the LSD test. ${ }^{*}$ and ${ }^{* *}$ represent significant differences at $P<0.05$ and $P<0.01$, respectively.

508 在中低氮条件下有较强的氮素吸收、积累速率 等氮代谢能力 ${ }^{[37-38]}$, 以及较高的光合生产与干物质 积累能力 ${ }^{[36]}$ 。在本研究中, 这一差异也引起了品种间 生育后期营养器官干物质和碳水化合物积累、转运量 及其对籽粒的贡献率对氮肥水平的响应的不同。

花前的物质积累是提高花后光合生产的基础, 而花后的光合生产能力决定了籽粒产量 ${ }^{[39]}$ 。耐低氮 性品种正红 311 生育后期植株干物质和 NSC 积累 量均显著高于氮低效品种先玉 508 , 且正红 311 在中低 氮水平下 $\left(0 \sim 300 \mathrm{~kg} \mathrm{hm}^{-2}\right)$ 的优势较大。本研究表明, $0 \sim 150 \mathrm{~kg} \mathrm{hm}^{-2}$ 施氮量下, 正红 311 干物质和 NSC 转 运量及积累量较先玉 508 更高, 但二者转运率差别不 大。同时, 正红 311 在低氮条件下花后干物质和 NSC 的积累对籽粒干重以及碳水化合物的贡献程度较高, 但花前转运量对籽粒贡献率不具优势。产量构成因 素在产量形成中的作用与品种特性和环境条件有 关 ${ }^{[40]}$ 。本研究中, 正红 311 植株干物质在花后的积累能 够促进玉米显著促进有效穗数增加, 进而提升产量;
而先玉 508 的百粒重受干物质积累的影响更明显, 过 多的物质转运反而不利于产量构成因素的建成。与 先玉 508 相比，正红 311，尤其在低氮条件下，保持 茎叶花前积累干物质向籽粒更合理(低)的转移比例, 以维持花后茎叶更高的光合物质生产(积累)量, 保 证植株穗部正常生长发育, 进而保证籽粒产量, 这 可能是正红 311 耐低氮的生理机制之一。

3.3 不同耐低氮性玉米品种生育后期氮素积累 与转运特性存在一定差异

米国华等 ${ }^{[7]}$ 认为玉米氮高效品种应该在生育后 期，充分利用前期高效吸收的氮，供给籽粒生长, 从而减少叶片中氮素的输出, 保证物质生产, 为籽 粒灌浆提供碳水化合物。郭松等 ${ }^{[41]}$ 认为最优的氮高 效品种要在花后吸氮能力强的基础上, 尽可能增加 营养器官中氮素向籽粒的转运, 从而保证产量提高 的同时, 籽粒含氮量得到稳定。本研究表明, 2 个品 种氮素转运量、转运率及其对籽粒的贡献程度存在 较大的年际差异, 这可能与降雨量和土壤肥力有 
表 6 籽粒产量与花前干物质、氮素和非结构性碳水化合物转运量及花后积累量的关系

Table 6 Relationship between grain yield and pre-silking translocation and post-silking accumulation of dry matter, nitrogen, and non-structural carbohydrates

\begin{tabular}{|c|c|c|c|c|c|c|c|c|c|c|}
\hline $\begin{array}{c}\text { 品种 } \\
\text { Cultivar }\end{array}$ & & $\begin{array}{c}\text { 籽粒产量 } \\
\text { Yield }\end{array}$ & $\begin{array}{c}\text { 有效穗数 } \\
\mathrm{EEN}\end{array}$ & $\begin{array}{c}\text { 穗粒数 } \\
\text { SPE }\end{array}$ & $\begin{array}{c}\text { 百粒重 } \\
100-\mathrm{KW}\end{array}$ & $\begin{array}{c}\text { 花前干物 } \\
\text { 质转运量 } \\
\text { DRA }\end{array}$ & $\begin{array}{c}\text { 花后干物 } \\
\text { 质积累量 } \\
\text { DAA }\end{array}$ & $\begin{array}{c}\text { 花前氮素 } \\
\text { 转运量 } \\
\text { NRA }\end{array}$ & $\begin{array}{c}\text { 花后氮素 } \\
\text { 积累量 } \\
\text { NAA }\end{array}$ & $\begin{array}{c}\text { 花前 NSC } \\
\text { 转运量 } \\
\text { NSCRA } \\
\end{array}$ \\
\hline \multirow[t]{9}{*}{ ZH 311} & 有效穗数 ENN & $0.89^{* *}$ & & & & & & & & \\
\hline & 穗粒数 SPE & $0.80^{* *}$ & 0.64 & & & & & & & \\
\hline & 百粒重 100-KW & $0.72^{*}$ & 0.64 & 0.18 & & & & & & \\
\hline & 花前干物质转运量 DRA & -0.30 & -0.41 & 0.21 & $-0.72^{*}$ & & & & & \\
\hline & 花后干物质积累量 DAA & $0.87^{* *}$ & $0.89^{* *}$ & 0.66 & 0.64 & -0.55 & & & & \\
\hline & 花前氮素转运量 NRA & 0.62 & 0.39 & $0.88^{* *}$ & 0.04 & 0.44 & 0.31 & & & \\
\hline & 花后氮素积累量 NAA & 0.31 & 0.28 & -0.22 & $0.82^{* *}$ & $-0.72^{*}$ & 0.36 & -0.44 & & \\
\hline & 花前 NSC 转运量 NSCRA & -0.49 & $-0.68^{*}$ & 0.01 & $-0.72^{*}$ & $0.83^{* *}$ & -0.62 & 0.16 & -0.49 & \\
\hline & 花后 NSC 积累量 NSCAA & $0.88^{* *}$ & $0.92^{* *}$ & $0.72^{*}$ & 0.54 & -0.43 & $0.96^{* *}$ & 0.45 & 0.14 & -0.63 \\
\hline \multirow[t]{9}{*}{ XY 508} & 有效穗数 ENN & 0.63 & & & & & & & & \\
\hline & 穗粒数 SPE & 0.51 & -0.33 & & & & & & & \\
\hline & 百粒重 $100-\mathrm{KW}$ & $0.82^{* *}$ & $0.85^{* *}$ & 0.01 & & & & & & \\
\hline & 花前干物质转运量 DRA & $-0.78^{*}$ & -0.28 & $-0.68^{*}$ & -0.39 & & & & & \\
\hline & 花后干物质积累量 DAA & $0.97^{* *}$ & 0.67 & 0.43 & $0.85^{* *}$ & $-0.79^{*}$ & & & & \\
\hline & 花前氮素转运量 NRA & 0.25 & $0.68^{*}$ & -0.53 & $0.73^{*}$ & 0.30 & 0.26 & & & \\
\hline & 花后氮素积累量 NAA & 0.53 & $0.92^{* *}$ & -0.42 & $0.90^{* *}$ & -0.04 & 0.58 & $0.88^{* *}$ & & \\
\hline & 花前 NSC 转运量 NSCRA & $-0.74^{*}$ & $-0.78^{*}$ & -0.01 & $-0.80^{* *}$ & 0.65 & $-0.81^{* *}$ & -0.43 & $-0.69^{*}$ & \\
\hline & 花后 NSC 积累量 NSCAA & $0.91^{* *}$ & $0.68^{*}$ & 0.34 & $0.83^{* *}$ & $-0.81^{* *}$ & $0.98^{* *}$ & 0.24 & 0.58 & $-0.86^{* *}$ \\
\hline
\end{tabular}

${ }^{*}$ 和 ${ }^{* *}$ 分别代表 $P<0.05$ 和 $P<0.01$ 显著水平。相关分析计算仅用 2018-2019 年数据 $(n=24,2$ 年 4 氮处理 3 重复)。

ZH311: Zhenghong 311; XY508: Xianyu 508.Yield: grain yield; EEN: efficient ear number; SPE: spike per ear; 100-KW: 100-kernel weight; DRA: dry matter translocation amount of pre-silking; DAA: dry matter accumulation amount of post-silking; NRA: nitrogen translocation amount of pre-silking; NAA: nitrogen accumulation amount of post-silking; NSCRA: NSC translocation amount of pre-silking; NSCAA: NSC accumulation amount of post-silking. ${ }^{*}$ and ${ }^{* *}$ represent significant differences at $P<0.05$ and $P<0.01$, respectively. The data from 2018 to 2019 are used for correlation analysis ( $n=24,2$ years, $4 \mathrm{~N}$ treatments and 3 replicates).

关。2018 年降雨量 $(1374.1 \mathrm{~mm})$ 较 2019 年 $(776.2 \mathrm{~mm})$ 高近 2 倍, 尤其是吐丝至灌浆期。大量的降水可能导 致氮素等养分流失, 根系对土壤氮素吸收量降低 ${ }^{[13,27]}$ 。 2018 年土壤含氮量较 2019 年高, 表明在土壤肥力较 高时(2018 年), 正红 311 利用其强大的氮素吸收能

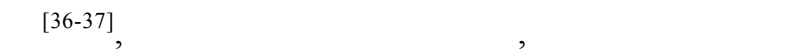
氮素向籽粒的转运量及其贡献率也就较高; 而在土 壤肥力较低时(2019 年), 由于花前吸收积累的氮素 相对较少, 花后积累的氮素及其对籽粒的贡献率就 相对较高; 先玉 508 两年花前氮素转运和花后氮素积 累对籽粒的贡献率变化较小, 氮素花后积累对籽粒 的贡献率均较高, 因此增施氮肥延缓根系衰老, 增 加花后氮素积累对增加其籽粒氮积累显得尤其重 要。与正红 311 不同, 先玉 508 籽粒产量及其构成 因素受氮素转运量、转运率的影响较大。适宜的氮 素转移、积累的能够为营造玉米吐丝前后良好的营
养条件通过提高有效穗数和穗粒数, 提高结实率, 减少籽粒败育, 利于高产 ${ }^{[42]}$

综上所述, 正红 311 在中低氮条件下, 花前干物 质和氮素的转运率较先玉 508 差异不大, 但其花后积 累能力较强, 表明正红 311 能够在花后保持较强的代 谢和光合生产能力以保证充足的碳水化合物供应。 供氮不足时, 正红 311 营养器官较高的物质积累量为 籽粒灌浆提供更充足的花前物质基础, 同时具有更 强的氮素积累(吸收)能力, 在一定程度上保证了花 后光合产物的合成 ${ }^{[20,43]}$ 。面对低氮胁迫, 正红 311 在保证花前咜存物质充分向籽粒运输的同时，维持 着较高的同化物积累能力, 以弥补缺氮造成的产量 损失。值得注意的是, 尽管 2 个品种的籽粒产量随 施氮量增加而提高, 但收获指数随施氮量减小, 且 增施氮肥对先玉 508 产量的促进更大。正红 311 的 产量优势随施氮量的增加而减小, 在 $450 \mathrm{~kg} \mathrm{hm}^{-2}$ 施 
氮量下其产量较 $300 \mathrm{~kg} \mathrm{hm}^{-2}$ 降低了 $1.24 \%$ 。在实际 生产中, 对耐低氮品种进行种适度减氮以促进花前 物质向籽粒的转运, 提高收获指数, 避免植株徒长 旺长和资源的浪费; 对低氮敏感品种, 可适当增施 氮肥以激发其产量潜力。

\section{4 结论}

供氮不足时，玉米通过增加花前咜存碳、氮物 质对籽粒的转运以保证产量。增施氮肥能够提高玉 米花后干物质和碳水化合物生产及其对籽粒质量的 贡献率。与低氮敏感品种先玉 508 相比, 耐低氮品 种正红 311 在低氮条件下，正红 311 在花前、花后均 保持较高的植株干物质、NSC 和氮素积累量, 花后 物质积累量及其对籽粒质量的贡献率更高, 从而拥 有更高的籽粒产量; 品种间花前物质转运率及其对 籽粒质量的贡献率差异不大。面对低氮胁迫, 正红 311 既保证了花前沄存物质充分向籽粒运输，同时维 持着较高的同化物积累能力来影响其产量形成。

\section{References}

[1] 郭皓升. 中国玉米产业面临的挑战与机遇. 现代管理科学, 2020, (2): 31-33.

Guo H S. Challenges and opportunities for China's corn industry. Modern Manage Sci, 2020, (2): 31-33 (in Chinese).

[2] Liu X J, Zhang Y, Han W X, Tang A, Shen J L, Cui Z L, Vitousek P J, Erisman J W, Goulding K, Christie P, Fangmeier A, Zhang F S. Enhanced nitrogen deposition over China. Nature, 2013, 494: $459-462$.

[3] Kong X B. China must protect high-quality arable land. Nature, 2014, 506: 7 .

[4] 张卫峰, 马林, 黄高强, 武良, 陈新平, 张福锁. 中国氮肥发 展、贡献和挑战. 中国农业科学, 2013, 46: 3161-3671.

Zhang W F, Ma L, Huang G Q, Wu L, Chen X P, Zhang F S. The development and contribution of nitrogenous fertilizer in China and challenges faced by the country. Sci Agric Sin, 2013, 46: 3161-3671 (in Chinese with English abstract).

[5] Wu Y W, Zhao B, Li Q, Kong F L, Du L J, Zhou F, Shi H C, Ke Y P, Liu Q L, Feng D J, Yuan J C. Non-structural carbohydrates in maize with different nitrogen tolerance are affected by nitrogen addition. PLoS One, 2019, 14: e225753.

[6] 李强, 罗延宏, 谭杰, 孔凡否, 杨世民, 袁继超. 玉米杂交种 苗期耐低氮指标的篮选与综合评价. 中国生态农业学报, 2014, 22: 1190-1199.

Li Q, Luo Y H, Tan J, Kong F L, Yang S M, Yuan J C. Indexes screening and comprehensive evaluation of low nitrogen tolerance of hybrid maize cultivars at seedling stage. Chin $J$ Eco-Agric, 2014, 22: 1190-1199 (in Chinese with English abstract).

[7] 米国华, 陈范骏, 春亮, 郭亚芬, 田秋英, 张福锁. 玉米氮高 效品种的生物学特征. 植物营养与肥料学报. 2007, 13: 155-159.
Mi G H, Chen F J, Chun L, Guo Y F, Tian Q Y, Zhang F S. Biological characteristics of nitrogen efficient maize genotypes. Plant Nutr Fert Sci, 2007, 13: 155-159 (in Chinese with English abstract).

[8] Moll R H, Kamprath E J, Jackson W A. Analysis and interpretation of factors which contribute to efficiency of $\mathrm{N}$ utilization. Agron J, 1982, 74: 562-564.

[9] 钟思荣, 龚丝雨, 张世川, 陈仁霄, 刘齐元, 翟小清. 作物不 同基因型耐低氮性和氮效率研究进展. 核农学报, 2018，32: 1656-1663.

Zhong S R, Gong S Y, Zhang S C, Chen R X, Liu Q Y, Zhai X Q. Research progress on low nitrogen tolerance and nitrogen efficiency in crop plants. Acta Agric Nuc Sin, 2018, 32: 1656-1663 (in Chinese with English abstract).

[10] Plénet D, Lemaire G. Relationships between dynamics of nitrogen uptake and dry matter accumulation in maize crops. Determination of critical N concentration. Plant Soil, 2000, 216: 65-82.

[11] Ning P, Yang L, Li C J, Fritschi F B. Post-silking carbon partitioning under nitrogen deficiency revealed sink limitation of grain yield in maize. $J$ Exp Bot, 2018, 69: 1707-1719.

[12] 马剑, 张钰. 分期追施氮肥对玉米营养器官中非结构性碳水 化合物积累转运及产量的影响. 玉米科学, 2019, 27(2): $155-160$.

Ma J, Zhang Y. Effect of topdressing nitrogen on transportation and accumulation of non-structural carbohydrate of vegetative organs and yield in maize. J Maize Sci, 2019, 27(2): 155-160 (in Chinese with English abstract).

[13] 武文明, 陈洪俭, 王世济, 魏凤珍, 李金才. 氮肥运筹对苗期 受渍夏玉米干物质和氮素积累与转运的影响. 作物学报, 2015, 41: 1246-1256.

Wu W M, Chen H J, Wang S J, Wei F Z, Li J C. Effects of nitrogen fertilization application regime on dry matter, nitrogen accumulation and transportation in summer maize under waterlogging at the seedling stage. Acta Agron Sin, 2015, 41: 1246-1256 (in Chinese with English abstract).

[14] 茩建峰, 董朋飞, 王秀玲, 刘卫玲, 李潮海. 氮肥运筹对不同 夏玉米品种碳氮代谢协调性的影响. 中国农业科学, 2017, 50: 2282-2293.

Chang Y F, Dong P F, Wang X L, Liu W L, Li C H. Effect of nitrogen application on carbon and nitrogen metabolism of different summer maize varieties. Sci Agric Sin, 2017, 50: 2282-2293 (in Chinese with English abstract).

[15] Chen F J, Mi G H. Comparison of nitrogen accumulation and nitrogen utilization efficiency between elite inbred lines and the landraces of maize. Acta Agric Scandinavica, Section B: Soil Plant Sci, 2012, 62: 565-569.

[16] 温立玉, 薛艳芳, 张慧, 张秀清, 高英波, 刘开昌, 李宗新. 不 同氮效率玉米品种亲本自交系花粒期氮素转运特性. 植物营 养与肥料学报, 2019, 25: 568-578.

Wen L Y, Xue Y F, Zhang H, Zhang X Q, Gao Y B, Liu K C, Li Z $\mathrm{X}$. The characteristics of nitrogen translocation of maize inbred lines with different nitrogen efficiency from anthesis to maturity. Plant Nutr Fert Sci, 2019, 25: 568-578 (in Chinese with English abstract).

[17] 陈延玲. 协调玉米高产与氮高效转运的机制. 中国农业大学 博士学位论文, 北京, 2015. pp 83-85. 
Chen Y L. Mechanisms for Coordination of High Yield and High Nitrogen Remobilization Efficiency in Maize. PhD Dissertation of China Agricultural University, Beijing, China, 2016. pp 83-85 (in Chinese with English abstract).

[18］李强, 孔凡否, 袁继超. 年际气象差异对西南丘陵区玉米物质 积累与产量的影响. 作物杂志, 2020, (4): 150-157.

Li Q, Kong F L, Yuan J C. Effects of inter annual meteorological differences on material accumulation and yield of maize in hilly area of southwest China. Crops, 2020, 4: 150-157 (in Chinese with English abstract).

[19] 张颖. 北方春玉米不同生育期干物质积累与氮、磷、钾含量的 变化. 玉米科学, 1996, 4(1): 63-65.

Zhang Y. Dry matter accumulation and changes of nitrogen, phosphorus and potassium contents in spring maize at different growth stages in northern China. J Maize Sci, 1996, 4(1): 63-65 (in Chinese with English abstract).

[20] 李强, 马晓君, 程秋博, 豆攀, 余东海, 罗延宏, 袁继超, 孔凡 磊. 氮肥对不同耐低氮性玉米品种花后物质生产及叶片功能 特性的影响. 中国生态农业学报, 2016, 24(1): 17-26.

Li Q, Ma X J, Cheng Q B, Dou P, Yu D H, Luo Y H, Yuan J C, Kong F L. Effects of nitrogen fertilizer on post-silking dry matter production and leaves function characteristics of low-nitrogen tolerance maize. Chin J Eco-Agric, 2016, 24(1): 17-26 (in Chinese with English abstract).

[21] 张忠学, 刘明, 齐智娟. 喷灌条件下水氮用量对玉米氮素吸收 转运的影响. 农业机械学报, 2019, 50(8): 299-308.

Zhang X Z, Liu M, Qi Z J. Effect of water nitrogen dosage on nitrogen absorption and transformation of maize under sprinkler irrigation condition. Trans CSAM, 2019, 50(8): 299-308 (in Chinese with English abstract).

[22] 尹彩侠, 李前, 孔丽丽, 秦裕波, 王蒙, 于雷, 刘春光, 王立春, 侯云鹏. 控释氮肥减施对春玉米产量、氮素吸收及转运的影响. 中国农业科学, 2018, 51: 3941-3950.

Yin C X, Li Q, Kong L L, Qin Y B, Wang M, Yu L, Liu C G, Wang L C, Hou Y P. Effect of reduced controlled-release nitrogen fertilizer application on yield, nitrogen absorption and transportation of spring maize. Sci Agric Sin, 2018, 51: 3941-3950 (in Chinese with English abstract).

[23] 周培禄, 任红, 齐华, 赵明, 李从锋. 氮肥用量对两种不同类 型玉米杂交种物质生产及氮素利用的影响. 作物学报, 2017, 43: 263-276.

Zhou P L, Ren H, Qi H, Zhao M, Li C F. Effects of nitrogen application rates on dry matter productivity and nitrogen utilization of different type maize hybrids. Acta Agron Sin, 43: 263-276 (in Chinese with English abstract).

[24] 李永虎, 曹梦琳, 杜慧玲, 郭平毅, 张海颖, 郭美俊, 原向阳. 施肥位置及施肥量对杂交谷子干物质累积、转运和产 量的影 响. 中国农业科学, 2017, 52: 4177-4190.

Li Y H, Cao M L, Du H L, Guo P Y, Zhang H Y, Guo M J, Yuan $X$ Y. Effect of fertilization location and amount on dry matter accumulation, translocation and yield of hybrid millet. Sci Agric Sin, 2017, 52: 4177-4190 (in Chinese with English abstract).

[25] 顾朝剑, 杨海泉, 蒋卫利, 舒小丽, 张贵超, 吴先军, 陈晓琼. 不同颜色水稻品种的总蛋白、可溶性蛋白含量分析. 分子植 物育种, 2017, 15: 1035-1042.

Gu C J, Yang H Q, Jiang W L, Shu X L, Zhang G C, Wu X J,
Chen X Q. The content analysis of total protein and soluble protein in different colored rice varieties. Mol Plant Breed, 2017, 15: 1035-1042 (in Chinese with English abstract).

[26] 郑飞娜, 初金鹏, 张秀, 费立伟, 代兴龙, 贺明荣. 播种方式 与种植密度互作对大穗型小麦品种产量和氮素利用率的调控 效应. 作物学报, 2020, 46: 423-431.

Zheng F N, Chu J P, Zhang X, Fei L W, Dai X L, He M R. Interactive effects of sowing pattern and planting density on grain yield and nitrogen use efficiency in large spike wheat cultivar. Acta Agron Sin, 2020, 46: 423-431 (in Chinese with English abstract).

[27] Li Q, Kong F L, Wu Y W, Feng D J, Yuan J C. Increasing nitrogen accumulation and reducing nitrogen loss with N-efficient maize cultivars. Plant Prod Sci, 2020, 23: 260-269.

[28] 潘俊峰, 崔克辉, 向镜, 魏冬, 王凯, 黄见良, 聂立孝. 不同库 容量类型基因型水稻茎鞘非结构性碳水化合物积累转运特征. 华中农业大学学报, 2015, 34(1): 9-15.

Pan J F, Cui K H, Xiang J, Wei d, Wang K, Huang J L, Nie L X. Characteristics of non-structural carbohydrate accumulation and translocation in rice genotypes with various sink-capacity. $J$ Huazhong Agric Univ, 2015, 34(1): 9-15 (in Chinese with English abstract).

[29] 杨明达, 关小康, 刘影, 崔静宇, 丁超明, 王静丽, 韩静丽, 王 怀苹, 康海平, 王同朝. 滴灌模式和水分调控对夏玉米干物质 和氮素积累与分配及水分利用的影响. 作物学报, 2019, 45: 443-459.

Yang M D, Guan X K, Liu Y, Cui J Y, Ding C M, Wang J L, Han J L, Wang H P, Kang H P, Wang T C. Effects of drip irrigation pattern and water regulation on the accumulation and allocation of dry matter and nitrogen, and water use efficiency in summer maize. Acta Agron Sin, 2019, 45: 443-459 (in Chinese with English abstract).

[30] 吕晓, 牛善栋, 李振波, 黄贤金, 钟太洋. 中国耕地集约利用 研究现状及趋势分析. 农业工程学报, 2015, 31(18): 212-224.

Lyu X, Niu S D, Li Z B, Huang X J, Zhong T Y. Present situation and trends in research on cultivated land intensive use in China. Trans CSAE, 2015, 31(18): 212-224 (in Chinese with English abstract).

[31] Yu J J, Han J N, Wang R F, Li X X. Down-regulation of nitrogen/carbon metabolism coupled with coordinative hormone modulation contributes to developmental inhibition of the maize ear under nitrogen limitation. Planta, 2016, 244: 111-124.

[32] Masclaux C, Valadier M H, Brugiere N, Morot-Gaudry J F, Hirel B. Characterization of the sink/source transition in tobacco (Nicotiana tabacum L.) shoots in relation to nitrogen management and leaf senescence. Planta, 2000, 211: 510-518.

[33] 潘俊峰. 氮对水稻茎鞘非结构性碳水化合物积累转运特征的 影响及其遗传基础研究. 华中农业大学博士学位论文, 湖北 武汉, 2010. pp 9-10.

Pan J F. Effects of Nitrogen Treatments on Characteristics of Accumulation and Translocation of Nonstructural Carbohydrates in Stems and Their Genetic Basis. PhD Dissertation of Huazhong Agricultural University, Wuhan, Hubei, China, 2010. pp 9-10 (in Chinese with English abstract).

[34] 徐云姬, 许阳东, 李银银, 钱希昒, 王志琴, 杨建昌. 干湿交 替灌溉对水稻花后同化物转运和籽粒灌浆的影响. 作物学报, 
2018, 44: 554-568.

Xu Y J, Xu Y D, Li Y Y, Qian X Y, Wang Z Q, Yang J C. Effect of alternate wetting and drying irrigation on post-anthesis remobilization of assimilates and grain filling of rice. Acta Agron Sin, 2018, 44: 554-568 (in Chinese with English abstract).

[35] 徐云姬. 三种禾谷类作物强、弱势粒灌浆差异机理及其调控技 术. 扬州大学博士学位论文, 江苏扬州, 2016. pp 201-205.

Xu Y J. Mechanism in Filling Difference between Superior and Inferior Caryopses of Three Cereal Crops and Its Regulation Techniques. PhD Dissertation of Yangzhou University, Yangzhou, Jiangsu, China, 2016. pp 201-205 (in Chinese with English abstract).

[36] Wu Y, Li Q, Jin R, Chen W, Liu X L, Kong F L, Ke Y P, Shi H C, Yuan J C. Effect of low-nitrogen stress on photosynthesis and chlorophyll fluorescence characteristics of maize cultivars with different low-nitrogen tolerances. J Integr Agric, 2019, 18: 1246-1256.

[37] 李强, 马晓君, 程秋博, 豆攀, 余东海, 罗延宏, 孔凡磊, 袁继 超. 氮肥对不同耐低氮性玉米品种氮素吸收利用及氮素平衡 的影响. 水土保持学报. 2016,30(3): 171-176.

Li Q, Ma X J, Cheng Q B, Dou P, Yu D H, Luo Y H, Kong F L, Yuan J C. Effects of nitrogen application on nitrogen utilization and nitrogen balance in fields of maize cultivars with different low nitrogen tolerance. J Soil Water Conserv, 2016, 30(3): 171-176 (in Chinese with English abstract).

[38] Li Q, Wu Y W, Chen W, Jin R, Kong F L, Ke Y P, Shi H C, Yuan J C. Cultivar differences in root nitrogen uptake ability of maize hybrids. Front Plant Sci, 2017, 8: 1060.

[39] 秦俭, 杨志远, 孙永健, 徐徽, 马均. 不同穗型杂交籼稻物质 积累、氮素吸收利用和产量的差异比较. 中国水稻科学, 2014, 28: 514-522.

Qin J, Yang Z Y, Sun Y J, Xu H, Ma J. Differential comparison of assimilation products accumulation, nitrogen uptake and utilization and grain yield of hybrid indica rice combinations with different panicle types. Chin J Rice Sci, 2014, 28: 514-522 (in
Chinese with English abstract)

[40] 穆心愿, 赵霞, 谷利敏, 冀保毅, 丁勇, 张凤启, 张君, 齐建双, 马智艳, 夏来坤, 唐保军. 秸秆还田量对不同基因型夏玉米产 量及干物质转运的影响. 中国农业科学, 2020, 53: 29-41.

Mu X Y, Zhao X, Gu L M, Ji B Y, Ding Y, Zhang F Q, Zhang J, Qi J S, Ma Z Y, Xia L K, Tang B J. Effects of straw returning amount on grain yield, dry matter accumulation and transfer in summer maize with different genotypes. Sci Agric Sin, 2020, 53: 29-41 (in Chinese with English abstract).

[41] 郭松, 孙文彦, 顾日良, 王章奎, 陈范骏, 赵秉强, 袁力行, 米 国华. 两个玉米品种灌浆期叶片氮转移效率差异的分子机制. 植物营养与肥料学报, 2018, 24: 1149-1157.

Guo S, Sun W Y, Gu R L, Wang Z K, Chen F J, Zhao B Q, Yuan L X, Mi G H. Differences in leaf nitrogen remobilization efficiency and related gene expression during grain filling stage of two maize hybrids. Plant Nutr Fert Sci, 2018, 24: 1149-1157 (in Chinese with English abstract).

[42] 魏廷邦, 胡发龙, 赵财, 冯福学, 于爱忠, 刘畅, 柴强. 氮肥后 移对绿洲灌区玉米干物质积累和产量构成的调控效应. 中国 农业科学, 50: 2916-2927.

Wei T B, Hu F L, Zhao C, Feng F X, Yu A Z, Liu C, Chai Q. Response of dry matter accumulation and yield components of maize under $\mathrm{N}$-fertilizer postponing application in oasis irrigation areas. Sci Agric Sin, 50: 2916-2927 (in Chinese with English abstract).

[43] 李强, 马晓君, 程秋博, 豆攀, 余东海, 罗延宏, 袁继超, 孔凡 磊. 氮肥对不同耐低氮性玉米品种干物质及氮素积累与分配 的影响. 浙江大学学报 (农业与生命科学版), 2015, 41: 527-536.

Li Q, Ma X J, Cheng Q B, Dou P, Yu D H, Luo Y H, Yuan J C, Kong F L. Effects of nitrogen fertilizer on the accumulation and allocation of dry matter and nitrogen for maize cultivars with different low nitrogen tolerance. $J$ Zhejiang Univ (Agric Life Sci Edn), 2015, 41: 527-536 (in Chinese with English abstract). 